\title{
CREMA
}

Center for Research in Economics, Management and the Arts

\section{Smoking Bans, Cigarette Prices and Life Satisfaction}

Working Paper No. 2015-16 


\title{
Smoking Bans, Cigarette Prices and Life Satisfaction *
}

\author{
Reto Odermatt ${ }^{\dagger}$ and Alois Stutzer ${ }^{\ddagger}$
}

August 31, 2015

\begin{abstract}
The consequences of tobacco control policies for individual welfare are difficult to assess, even more so when related consumption choices challenge people's willpower. We therefore evaluate the impact of smoking bans and cigarette prices on subjective well-being by analyzing data for 40 European countries and regions between 1990 and 2011. We exploit the staggered introduction of bans and apply an imputation strategy to study the effect of antismoking policies on people with different propensities to smoke. We find that higher cigarette prices reduce the life satisfaction of likely smokers. Overall, smoking bans are barely related to subjective well-being, but increase the life satisfaction of smokers who would like to quit smoking. The latter finding is consistent with cue-triggered models of addiction and the idea of bans as self-control devices.
\end{abstract}

Keywords: Smoking bans, cigarette prices, life satisfaction, addiction, self-control

JEL classification: D03, D62, H25, H30, I18

\footnotetext{
${ }^{*}$ This is a revised version for the Journal of Health Economics. We are grateful to Thomas Brändle, Francesca Cornaglia, Paul Dolan, Jan De Neve, Bruno Frey, Thorsten Henne, Andreas Kuhn, David Laibson, Markus Ludwig, Simon Lüchinger, Guy Mayraz, Ulrich Matter, Michaela Slotwinski, Andrew Oswald and Matthew Rabin, as well as participants at the meetings of the AEA, EEA, EPCS, IIPF and SSES, the conferences on Markets and Happiness, on Public Happiness and on the measurement of SWB at the OECD, the seminars at DIW Berlin, LSE, and the Universities of Basel, Lausanne, Torino, Zaragoza and Zurich for helpful comments, and to Charlotte Ruetz for excellent research assistance. Reto Odermatt acknowledges financial support from the WWZ Forum. This paper is a substantially extended version of our conference paper entitled "Smoking bans and life satisfaction in Europe" of March 2011.

${ }^{\dagger}$ University of Basel, Faculty of Business and Economics, Peter Merian-Weg 6, 4002 Basel, Switzerland. Phone: +41 (0)61 26733 70, fax: +41 (0)61 26733 40, email: reto.odermatt@unibas.ch.

${ }^{\ddagger}$ University of Basel, Faculty of Business and Economics, Peter Merian-Weg 6, 4002 Basel, Switzerland. Phone: +41 (0)61 26733 61, fax: +41 (0)61 26733 40, email: alois.stutzer@unibas.ch.
} 


\section{Introduction}

Adverse health effects of smoking motivate tobacco control policies in many countries. Most prominent are smoking bans introduced at workplaces as well as in restaurants, bars and clubs. Moreover, excise taxes are levied on tobacco products in order to increase their prices. These policies, however, are controversially discussed, as they have a multitude of consequences affecting people's health and welfare in various ways with sometimes countervailing effects.

At first sight, non-smokers are expected to be the primary beneficiaries of these policies, for example, by positive effects on health due to the potential protection from environmental tobacco smoke (see, e.g., Pell et al. 2008, Meyers et al. 2009 or Kuehnle and Wunder 2013). However, smoking bans might also lead to negative side effects such as the displacement of smoking from the targeted public places to officially unregulated private places (Adda and Cornaglia 2010). Smoking bans may then have negative welfare effects even for non-smokers.

For smokers, competing welfare predictions emerge for other reasons. From a traditional economic perspective (pioneered in the domain of addictive goods by Becker and Murphy 1988), public health interventions constrain smokers in their habits, and this tends to make them worse off. Benefits arise only to the extent that the policies successfully internalize social costs. However, from a behavioral economics perspective smokers may face self-control problems and are therefore unable to make short-term decisions according to their long-term preferences. For them, a policy that restricts smoking might have a positive impact on individual well-being as it can serve as a self-control device. According to the models of O'Donoghue and Rabin (1999) and Gruber and Köszegi (2001, 2004), smoking bans as well as higher cigarette prices substantially increase the costs of smoking and thus reduce the need to rely on willpower to adhere to a time-consistent consumption plan. In contrast, the models of $\mathrm{Gul}$ and Pesendorfer (2001) and Bernheim and Rangel (2004) predict that higher prices will have a negative welfare effect on smokers, as they have a limited effect in reducing overconsumption. The models rather emphasize that successful policy interventions have to protect people from tempting situations. Smoking bans might achieve this more directly than higher cigarette prices.

Thus, depending on the assumed time consistency in smokers' consumption behavior, different predictions for the welfare consequences of anti-smoking policies emerge. This holds even though the different models predict similar reactions to tobacco control policies in terms of smoking behavior. Accordingly, it is very difficult to discriminate between the theoretical perspectives based on observed consumption behavior. Still, previous research concentrates mainly on the impact on smoking behavior and health outcomes 1$]$ Furthermore, the partly countervailing

\footnotetext{
${ }^{1}$ The related literature is vast, in particular regarding the consequences of tobacco control policies on consumption behavior. For reviews on the economics of smoking and tobacco policy, see, e.g., Viscusi (1992), Chaloupka and Warner (2000), Gruber (2001), and Cnossen (2006). Generally, negative price elasticities in the range from -0.3 to -0.5 are found (Chaloupka and Warner 2000), whereby recent refined estimates report smaller elasticities (Tauras 2006). Similarly for smoking bans, recent analyses with refined identification strategies only find small negative effects on cigarette smoking (e.g., Adda and Cornaglia 2010, Carpenter et al. 2011, or Anger et al. 2011) compared to earlier reviews (see, e.g., Fichtenberg and Glantz 2002 or Hopkins et al. 2010).
} 
behavioral reactions and health consequences have rarely been assessed with regard to a net effect on people's well-being so far.

In this paper, we propose the use of data on subjective well-being as a complementary approach to study the welfare consequences of policies in areas that might involve suboptimal consumption choices 2 Such an approach allows capturing welfare effects due to the potential reduction of negative externalities as well as internalities. We thereby go beyond existing research and simultaneously analyze the net welfare effects of smoking bans and cigarette prices not only for smokers and non-smokers, but also for smokers who failed to stop smoking. The latter group potentially captures people with limited willpower. Besides a general policy evaluation, this approach enables us to test in an original way two classes of behavioral economic models and their relevance within the scope of large-scale health policy interventions.

We exploit repeated cross-sectional data from 41 waves of the Eurobarometer survey series which include 629,930 individuals from 40 European countries and regions between 1990 and 2011. The staggered introduction of smoking bans in the different countries and regions enables us to study the effect of the bans on individual life satisfaction in a difference-in-differences-type framework. Importantly, the investigation of the ban introduction process does not indicate concurring (health) policy interventions. Therefore, the developments of life satisfaction in regions and countries that do not introduce smoking bans in a given point of time can be studied as counterfactuals. The variation in cigarette prices over time is exploited to identify the consequences of higher prices on subjective well-being. The rich data pool allows us further to take into account unobserved country-specific effects, survey wave-specific effects, linear and quadratic country-specific time trends, and measures for macro-economic conditions as well as for other tobacco control activities.

The selection into a particular smoking status is taken into account when studying treatment effects for different groups such as likely smokers and non-smokers (thereby following and extending the approach pursued by Gruber and Mullainathan 2005). As tobacco control policies affect people's smoking status, individuals who indicate that they are smokers pre- and postintervention are not comparable. Some smokers might quit and are thus no longer observed in the group of smokers after the intervention. Any measured difference in subjective well-being for actual smokers consequently compounds a possible treatment effect and a selection effect. In our analysis, we instead concentrate on a counterfactual smoking status of every person in the sample for the case that no smoking ban is in place and cigarette prices are low.

We find, on average, a small positive partial correlation between the introduction of smoking bans and people's reported life satisfaction that more likely holds for smokers than for non-smokers; however, the effects here are rather imprecisely measured and not statistically significant. Higher cigarette prices are statistically weakly related to a lower level of reported subjective well-being. The strong negative effect that higher prices have on the life satisfaction of likely smokers drives

\footnotetext{
${ }^{2}$ For a general account see Köszegi and Rabin (2008), Stutzer (2009) and Hsee et al. (2012). Introductions to the economic analysis of subjective well-being are, e.g., provided in Frey and Stutzer (2002), Layard (2005) and Stutzer and Frey (2010). Applications to suboptimal consumption choices are, e.g., Stutzer and Meier (2015) on obesity and Benesch et al. (2010) on TV viewing.
} 
the negative correlation, whereas non-smokers are not affected by higher prices. Within the group of smokers, higher prices also reduce the life satisfaction of people who want to give up smoking. However, smokers in this latter group, report a higher level of life satisfaction when smoking bans are in place. These people (roughly one third of the smokers according to surveys) are likely to perceive smoking bans as a self-control device that helps them pursue their preferred consumption plan. Altogether, the findings question the idea that higher tobacco taxes act as an effective internalization strategy and self-control device, while the partialy positive effects of smoking bans are consistent with models of addiction based on cue-triggered decision processes.

The proposed negative effect of higher cigarette prices is contrary the prominent result published in the study by Gruber and Mullainathan (2005). In two longitudinal analyses across states of the United States and Canada, they find that higher tobacco taxes significantly reduce the likelihood of being unhappy among people who have a high propensity to smoke compared to people who have a low propensity to smoke. We discuss possible reasons for the difference in these results in Section 3.4. Our findings also relate to two other recent studies. In another analysis for the United States, Brodeur (2013) finds no differential effects of higher taxes on the life satisfaction of smokers compared to non-smokers. However, he reports a positive differential effect of smoking bans in bars and restaurants on smokers who do not quit smoking following the implementation of the ban. Using data from the British Household Panel Survey and relying on the different introduction dates across the four regions in the United Kingdom, Leicester and Levell (2013) find no robust effect for the introduction of smoking bans on mental well-being. With regard to higher cigarette taxes, they find a positive differential effect on the well-being of smokers compared to non-smokers. However, if the negative baseline effect for non-smokers - who serve as the control group - are taken into account, the net effect for smokers remains ambiguous.

Our analysis complements and extends the specific studies for Canada, the United Kingdom and the United States in several ways. First, we compile and analyze the largest available dataset on tobacco control policies and subjective well-being for Europe so far. The large variation in the introduction dates of bans and in country-specific cigarette prices allow us to assess tobacco control policies in an econometrically rigorous way. Moreover, since Europe is a region with high average smoking rates, any policy might have a potentially bigger impact than in the United States, where smoking is socially less well accepted and smoking prevalence is lower. Second, we simultaneously analyze the welfare effects of smoking bans and cigarette prices while controlling for a set of additional tobacco control policies such as restrictions on advertising as well as for anti-alcohol policies in terms of taxation. This reduces the risk of potential omitted variable bias. In addition, we take into account that the comprehensiveness of the bans differs across countries and regions. Third, previous studies use non-smokers as a control group and focus solely on the differential effects of tobacco policies on smokers compared to non-smokers. However, the same policies might affect the non-smokers as well. We identify and evaluate the net welfare effects of the policies on both groups. Empirically, the net welfare effect for likely smokers is obtained from the linear combination of the main effect for likely non-smokers and the differential effect for likely smokers. And fourth, previous research has not yet performed a distinctive test of the 
different welfare predictions that emerge from different classes of behavioral economic models. We analyze whether likely smokers who recently tried, but failed to quit smoking, are differently affected by the introduction of smoking bans compared to an increase in cigarette prices. This approach offers a first attempt to empirically discriminate between the theoretical models.

The remainder of this paper is organized as follows. In Section 2, we describe the institutional background regarding the regulation of smoking in Europe and present the data. Section 3 explains our empirical strategy and reports the average effects of bans and cigarette prices on reported life satisfaction, as well as the specific effects for likely smokers and non-smokers. In Section 4, we focus on smokers who tried to quit smoking in the recent past, but relapsed. We explore how these people's life satisfaction is affected by the alternative tobacco control policies. We discuss these policies' relative effectiveness as collective self-binding mechanisms. Section 5 offers concluding remarks.

\section{Institutional Background and Data}

\subsection{Tobacco Control Policies in the European Union}

The two main policy variables in our analysis are smoking bans and cigarette taxes as reflected in prices. Smoking bans are public policies promoted, in particular, by the WHO Framework Convention in Tobacco Control (FCTC). In response to the ratification of the treaty, many countries introduced smoking bans in indoor workplaces, in indoor public places, in public transport and in bars and restaurants; i.e., the hospitality sector. The first country in Europe that banned smoking comprehensively was Ireland in March 2004. In the meantime, almost all European countries know some sort of spatial smoking restriction. While in some countries and regions the introduction of the ban occurred on the same date, by spring 2011, there were a total of 30 different introduction dates for bans in the 40 countries and regions in our sample.

Some countries first introduced bans only in workplaces. In a second introduction phase, the bans were then extended to the hospitality sector. This occurred in Austria, Belgium, Estonia, France, the Netherlands and Slovakia. In Latvia the ban in the hospitality sector was tightened four years after its implementation. We also take account of the fact that the comprehensiveness of the bans differs across the countries and regions. For these particularities, we use the scores of the Tobacco Control Scale (TCS) (Joossens and Raw 2006, 2007, 2011) to qualify the bans. The TCS reflects the results of expert surveys regarding tobacco control activities in the European countries. We use the sum of the sub-scale scores for smoke-free policies in workplaces (max. ten points) and for the bans in the hospitality sector (max. eight points) and divide this value by the maximum achievable scores in order to build an index $[0,1]$ that reflects the comprehensiveness of the bans. In turn, our variable smoking ban st $_{t}$ takes the value of the index for country/region $j$ at time $t$ when a ban is introduced. For example, for Italy the variable, smoking ban, takes the value zero before November, 10, 2005, and the value 0.78 afterwards (with sub-scale scores of eight out of ten for the ban in workplaces and six out of eight for the ban in the hospitality 
sector). Table A.3 in the Appendix gives an overview of the countries' and regions' introduction dates in our sample together with the assigned scores from the TCS.

Information on the tax structures of tobacco products and cigarette prices in European countries is provided at least once a year in the Excise Duty Tables from the European Commission (19902011b). From this data, we use the information on the overall excise tax as well as the price of cigarettes from the most popular price category (MPPC) per 1000 cigarettes in euros $3^{3}$ To make the prices comparable across countries, we adjust them for the country-specific price levels and report them in 2005 euros. The average real cigarette price (in 2005 euros) in the sample is 162.1 euros per 1,000 cigarettes (or 3.42 euros per package of 20 cigarettes) with a standard deviation of 60.8 . The associated average overall excise tax is 122.3 euros. In some countries, the tax constitutes up to 90 percent of the retail price. Figure A.1 provides an overview of the variation in the price and the overall excise tax on cigarettes across countries and over time. It is clearly visible that taxes are the main driver of cigarette prices.

Besides the major policies involving bans and taxes, there are a series of other tobacco control measures in place in various European countries. In order to capture them, we again make use of the TCS. We sum the sub-scale scores for regulations regarding direct health warnings on cigarette packages (max. ten points), bans on advertising and promotion (max. thirteen points), and treatments that help dependent smokers stop smoking (max. ten points). For every country, we apply this sum of the sub-scale scores, provided for the years 2005, 2007 and 2010 , as a supplementary tobacco control measure.

\subsection{Individual- and Country-Level Data}

In our empirical analysis, the policy variables are linked to individual-level data from the Eurobarometer surveys (EB) that include a question on people's subjective well-being (European Commission 2012). The EB is a repeated cross-section survey in the member states of the European Union. Our analysis consists of 22 European countries; i.e., Austria, Belgium, Cyprus (Republic of), Denmark, Estonia, Finland, France, Germany, Ireland, Italy, Latvia, Lithuania, Luxembourg, Malta, the Netherlands, Portugal, Romania, Slovakia, Slovenia, Spain, Sweden and the United Kingdom. For the United Kingdom, the entities England, Scotland, Wales and Northern Ireland and for Germany, the 16 German Laender are considered as separate geographical units, since the smoking bans were not introduced nationwide simultaneously in these places. We use data from 41 survey waves between 1990 and 2011. For Austria, Finland and Sweden, data is only available from the beginning of 1995 and for the newest members of the EU (i.e., Cyprus, Estonia, Latvia, Lithuania, Malta, Slovenia, Slovakia and Romania) from the beginning of 2004 .

Our dependent variable is based on a survey question on people's life satisfaction. On a fourpoint scale, people answer the question "On the whole, are you very satisfied, fairly satisfied, not very satisfied, or not at all satisfied with the life you lead?". "Very satisfied" is coded as four,

\footnotetext{
${ }^{3}$ For France, Latvia, Lithuania, Luxembourg, Poland and the UK, no MPPC cigarette prices are reported in 2011. Accordingly, no EB observations from these countries are included in 2011.
} 
"not at all satisfied" as one. The average satisfaction level in the sample is 3.05 with a standard deviation of 0.74 . Based on further survey questions, a number of socio-demographic and socioeconomic characteristics are taken into account. Table A.1 in the Appendix offers descriptive statistics for the included individual-level variables from the EB, and Table A.2 lists the surveys and data sources that are used. From the listed survey waves, we include all observations except for people who refused to indicate their marital status or who did not know what age they were when they finished their education. Individuals who do not report the number of children in their household are indicated by a separate indicator. The final sample consists of 629,930 observations.

The empirical analysis takes a number of aggregate economic indicators into account as control variables: i.e., the country-specific nominal GDP per capita, the inflation rate, and the rate of unemployment. Information is derived from the national statistics of the European Commission and the OECD. Data on the region-specific unemployment rate for Germany is provided by the German Federal Employment Agency (for 1991 to 2011) and for the United Kingdom by the Welsh Government (see Table A.2 in the Appendix for further information on the data sources). To control for potential correlation between the excise tax on cigarettes and other excise taxes, we additionally compiled yearly data on the country-specific taxation of beer per degree of alcohol (European Commission 1990-2011a). We adjust the beer tax with the country-specific price level to obtain the real tax (in 2005 euros).

\section{Tobacco Control Policies and Life Satisfaction}

\subsection{Empirical Strategy}

Based on reported satisfaction with life as the dependent variable, we directly assess the consequences of smoking bans and higher cigarette prices on our proxy for individuals' welfare. To identify the effect of smoking bans, we exploit the quasi-random experiment provided by the staggered introduction of smoking bans across European countries and regions. Our key identifying assumption is that countries and regions that introduced a smoking ban would have experienced the same changes in subjective well-being as other countries and regions had they not introduced the ban. We deal with this key assumption in three ways. First, we checked whether the introduction of the bans did not occur simultaneously with other (health-related) policies. An examination of the introduction processes in the countries reveals that only in England and Wales the implementation of the ban was part of a health act governing different aspects of public health 4 The exclusion of these regions from the sample does not lead to qualitatively different results in the empirical analysis though. However, other regulations of consumption goods might still be correlated with the implementation of bans. We therefore include information on other concurrent tobacco control policies described in Section 2.1 and

\footnotetext{
${ }^{4}$ The examination is based on information from official documents of the European Commission and from a project of the International Legal Consortium that is part of the campaign for Tobacco-Free Kids (see www.tobaccocontrollaws.org).
} 
on the real state-specific tax on beer per degree of alcohol in each country as additional control variables.

Second, we focus on within-country or regional variation for the measurement of the effect by taking into account country and region fixed effects (together with survey-wave fixed effects controlling for common time-specific shocks). Third, we deal with potential unobserved changes over time that influence life satisfaction and could be correlated with the adoption of smoking bans. This, in turn, reduces the risk that the common trend assumption is violated. In particular, we estimate models with country-specific time trends (both linear and quadratic). This is important, because the timing of the adoption of the bans might not have been random. In an event history analysis for the EU, Toshkov (2013) finds that in countries where more tobacco leaves are produced, more cigarettes are smoked, and where public support for bans in bars is weaker, smoking bans are introduced later. To the extent that these factors are related to trends, they are not accounted for with country fixed effects alone, but we need to control for country-specific time trends.

The effect for cigarette prices is identified based on price variation within countries over time considering the same flexible control strategy for unobserved country specific trends as for the policy variable, smoking ban.

Specifically, we estimate regression equations of the following form:

$$
L S_{i j t}=\beta_{0}+\beta_{1} \operatorname{ban}_{j t}+\beta_{2} \ln (\text { price })_{j t}+\beta_{3} X_{i}+\beta_{4} Z_{j t}+\beta_{5} D_{j}+\beta_{6} D_{t}+\beta_{7}\left(D_{j} * \text { trend }\right)+\varepsilon_{i j t}
$$

The life satisfaction $L S_{i j t}$ of individual $i$ in country/region $j$ at time $t$ is regressed on an index variable $b a n_{j t}[0,1]$ that captures the manifestation of the policies in the specific country/region at the time of the survey. The second policy variable is $\ln (\text { price })_{j t}$ for the country-specific level of cigarette prices. As control variables, we include individual socio-demographic characteristics $X_{i}$; i.e., age, sex, level of education, marital status, number of children in the same household, and the occupation of the respondent.

The country-level control variables $Z_{j t}$ consist of the real GDP per capita in logarithmic form, while the rates of unemployment and inflation are in percent. All these variables have been identified as relevant covariates of reported subjective well-being in previous research and help us to prevent omitted variable bias and to increase the efficiency with which the effect of the aggregate variables capturing tobacco control policies are estimated. The vector of controls $Z_{j t}$ further includes the index for other tobacco control policies and the real state-specific tax on beer per degree of alcohol in each country. Further, we control for country-/region-specific effects $D_{j}$, survey wave-specific time effects $D_{t}$, and linear as well as quadratic country-specific time trends $D_{j}{ }^{*}$ trend $:^{5}$

\footnotetext{
${ }^{5}$ Region-specific effects are applied for Germany and the UK, where the introduction dates of the bans vary on the regional level. We include separate time trends for East Germany and West Germany and a common trend for the UK.
} 
Standard errors are clustered at the country/region level to correct for serial and intraclass correlation across individuals of the same country/region. We apply sample weights provided in the EB data file throughout to reproduce the real number of cases for each country.

\subsection{Overall Effects of Smoking Bans and Cigarette Prices}

Table1 1 presents the estimations for the overall effects of smoking bans and cigarette prices on life satisfaction based on OLS estimates ${ }^{6}$ Column I shows a positive change in life satisfaction after countries or regions have introduced or extended smoking bans, ceteris paribus. The introduction of a comprehensive smoking ban in both the hospitality sector as well as at workplaces is related to an increase in satisfaction by 0.03 points. This effect is not statistically significant though. For cigarette prices, we find a sizeable negative partial correlation with life satisfaction in column II. The estimate indicates that a fifty-percent price increase (slightly more than one standard deviation vis-à-vis the mean) is associated with a statistically significant decrease in the average level of satisfaction by 0.04 points on the four-point scale.

The separate evaluation of the two tobacco control policies might, however, be misleading if the policies are correlated and reflect different aspects of governments' activism in health prevention. Column III takes this concern into account and includes the two main policy measures together. Column IV includes the information on other concurrent tobacco control policies and on the tax on beer in each country as additional control variables. Both, the beer tax and other tobacco control policies, are not systematically related to subjective well-being. In column V, we add control variables that capture the macroeconomic conditions in a country/region, i.e., GDP per capita, the rate of unemployment, and the rate of inflation. With the inclusion of all these controls, the negative effect of cigarette prices remains sizeable, but is slightly smaller and less precisely measured compared to columns II to IV. The effect of a fifty-percent price increase relates to a decrease in life satisfaction of 0.02 points. This corresponds to the negative effect of an increase of the rate of unemployment by 2.7 percentage points. 7

\footnotetext{
${ }^{6}$ We apply OLS instead of ordered probit or ordered logit - which would take into account the ordinal nature of the dependent variable - because we include interaction terms later on, which makes the interpretation and comparison of effect sizes problematic with non-linear models (see, e.g. Ai and Norton 2003). However, the results from ordered probit estimations are qualitatively similar to the OLS estimates. Footnote 7 reports them for the estimation that includes all the control variables. Table A.4 reports the full regression outputs of the OLS specifications in Table 1 .

${ }^{7}$ If we estimate the specification in column $\mathrm{V}$ with an ordered probit model, we obtain the following coefficients for the main variables $\operatorname{ban}_{j t}: \beta_{1}=0.031\left(\mathrm{z}\right.$-value=1.10) and $\ln (\text { price })_{j t}: \beta_{2}=-0.088$ (z-value=-1.11). They are thus very similar in relative size and statistical significance to the coefficients based on the OLS estimation. The negative partial correlation for cigarette prices is also robust with regard to alternative scalings of the price measure. The coefficient $\beta_{2}$ is -0.028 ( $\mathrm{z}$-value $=-1.16$ ) if absolute real prices in 100 euros are considered and -0.029 $(\mathrm{z}$-value $=-1.46)$ if absolute current prices in 100 euros are taken into account.
} 
Table 1: Smoking bans, cigarette prices and life satisfaction in 40 European countries and regions, 1990-2011

Dependent variable: Life satisfaction

\begin{tabular}{|c|c|c|c|c|c|}
\hline & $\mathrm{I}$ & II & III & IV & $\mathrm{V}$ \\
\hline Smoking ban & $\begin{array}{r}0.025 \\
(1.52)\end{array}$ & & $\begin{array}{r}0.022 \\
(1.36)\end{array}$ & $\begin{array}{r}0.026 \\
(1.36)\end{array}$ & $\begin{array}{r}0.016 \\
(0.92)\end{array}$ \\
\hline $\ln ($ cigarette price $)$ & & $\begin{array}{l}-0.099^{* * *} \\
(-2.81)\end{array}$ & $\begin{array}{l}-0.097^{* * *} \\
(-2.74)\end{array}$ & $\begin{array}{l}-0.085^{* *} \\
(-2.08)\end{array}$ & $\begin{array}{l}-0.054 \\
(-1.13)\end{array}$ \\
\hline Other tobacco policies & & & & $\begin{array}{r}0.001 \\
(0.27)\end{array}$ & $\begin{array}{r}0.002 \\
(0.47)\end{array}$ \\
\hline $\ln ($ beer tax $)$ & & & & $\begin{array}{l}-0.042 \\
(-0.96)\end{array}$ & $\begin{array}{l}-0.028 \\
(-0.78)\end{array}$ \\
\hline $\ln ($ GDP per capita) & & & & & $\begin{array}{l}-0.034 \\
(-0.17)\end{array}$ \\
\hline Unemployment rate & & & & & $\begin{array}{l}-0.008 \\
(-1.39)\end{array}$ \\
\hline Inflation rate & & & & & $\begin{array}{r}0.004 \\
(1.35)\end{array}$ \\
\hline Individual characteristics & Yes & Yes & Yes & Yes & Yes \\
\hline Country/region FE & Yes & Yes & Yes & Yes & Yes \\
\hline Survey wave FE & Yes & Yes & Yes & Yes & Yes \\
\hline Linear country-spec. time trends & Yes & Yes & Yes & Yes & Yes \\
\hline Quadratic country-spec. time trends & Yes & Yes & Yes & Yes & Yes \\
\hline No. of observations & 629,930 & 629,930 & 629,930 & 629,930 & 629,930 \\
\hline No. of clusters & 40 & 40 & 40 & 40 & 40 \\
\hline $\mathrm{R}^{2}$ & 0.22 & 0.22 & 0.22 & 0.22 & 0.22 \\
\hline
\end{tabular}

Notes: OLS estimations. T-values in parentheses. Standard errors are clustered on the country/region level. Significance levels: ${ }^{*} .05<p<.1,{ }^{* *} .01<p<.05, * * *<.01$.

\subsection{Differential Effects Depending on the Propensity to Smoke}

Economic theory predicts different welfare consequences of anti-tobacco policies for smokers and non-smokers. Differential effects can, however, not be studied based on individuals' current smoking status. Non-smokers in a regime with smoking bans might well be smokers if this kind of restriction were not in place. Any observed effect for non-smokers would thus confound consequences for previous non-smokers and people who changed their status, and lead to a sample selection bias. Instead, we calculate for every individual in the sample the probability that he or she smokes given his or her individual characteristics. We call this probability the propensity to smoke. Based on this information, we test for differential effects of the policies following the strategy of Gruber and Mullainathan (2005).

We first estimate the partial correlations for a large number of covariates of being a current smoker. As there is no information about the smoking status of the individuals in the main dataset, we rely on an auxiliary dataset drawn from the Eurobarometer. It consists of survey information from eight waves between 1990 and 2009. In this first step, individual-level and country-specific variables as well as country-specific fixed effects and time trends are taken into 
account as covariates of smoking. We estimate the model separately for males and females (equivalent to specifying a full interaction model). This allows for differences in the pattern of men's and women's smoking behavior. Table A.5 shows the respective results of the logistic regression models. The estimated correlations are in line with empirically established relationships between socio-economic characteristics and smoking behavior: high levels of education, being married, and not being unemployed are related to a lower probability of being a smoker for men as well as for women. GDP per capita is positively related to smoking prevalence, while for women the rate of unemployment is positively related with the status of being a smoker, and the rate of inflation and the measure of other tobacco control policies are negatively related with the status of being a smoker. The two variables capturing our tobacco control policies of interest are not systematically correlated with self-reported smoking behavior. While somewhat surprising, this is consistent with the recent longitudinal evidence for Europe by Chaloupka et al. (2010) or Adda and Cornaglia (2010) for the United States.

The estimated partial correlations are then used in a second step to calculate for every individual in the main dataset the probability that he or she is a smoker based on his or her characteristics. The imputed propensity is denoted $p(\text { smoke })_{i}$. Hereby, the propensity to smoke is calculated for the counterfactual situation with no smoking ban in place, and cigarette prices are set to the lowest level in the time series of the respective country. Figure A.2 in the Appendix shows the distribution of the imputed probabilities of being a smoker in the main dataset 8

The two-step approach allows us to directly study the differential hypotheses about the welfare consequences of smoking bans and cigarette prices for people with low and high propensities to smoke. The regression model is extended to the following form:

$$
\begin{array}{r}
L S_{i j t}=\beta_{0}+\beta_{1} \text { ban }_{j t}+\beta_{2} p\left(\text { smoke }_{i}+\beta_{3} \text { ban }_{j t} \times p(\text { smoke })_{i}+\beta_{4} \ln (\text { price })_{j t}+\right. \\
\beta_{5} \ln \left(\text { price }_{j t} \times p\left({\text { smoke })_{i}}_{i}+\beta_{6} X_{i}+\beta_{7} Z_{j t}+\beta_{8} D_{t}+\beta_{9} D_{j}+\beta_{10}\left(D_{j} * \text { trend }\right)+\varepsilon_{i j t}\right.\right.
\end{array}
$$

Technically, we include interaction terms between the variables for the tobacco control policies and the variable capturing the estimated propensity to smoke. The main effect for smoking bans (or cigarette prices) then indicates the consequence of a ban (or a higher price) for people with a predicted probability to smoke of zero. The linear combination of the main effect plus the interaction effect indicates the consequence of a ban or a higher price for people with a predicted probability to smoke equal to one. Note that our empirical setup allows us to capture treatment effects for likely non-smokers as well as likely smokers. Non-smokers are not treated

\footnotetext{
${ }^{8} \mathrm{An}$ idea of the predictive power of our specification based on within sample predictions is provided by Figure A.3 in the Appendix. Of the people for whom we predict the lowest smoking propensities ( $1^{\text {st }}$ quartile), 12.4 percent report that they smoke. At the other end, for people with the highest smoking propensities $\left(4^{\text {th }}\right.$ quartile), 52.3 percent of the respondents declare that they are currently smokers. We also check the goodness-of-fit from a cross-tabulation of observed and predicted outcomes. To classify whether an individual is a smoker, we define the threshold-value for the predicted propensity to smoke in a way that produces the same number of predicted smokers as there are actual smokers in the dataset. Overall, we predict 71.1 percent of the cases correctly for females and 64.7 percent for males. The respective probabilities that we correctly identify an actual smoker (sensitivity) are 44.7 for females and 53 percent for males, while the fractions of correctly predicted non-smokers (specificity) are 80.4 for females and 71.8 percent for males.
} 
as a control group (given that many tobacco control policies are introduced inter alia to protect people from second-hand smoking). While the differential effect between likely non-smokers and likely smokers is interesting as such (we always present it as part of our output in the tables), it should not be confounded with the net welfare effect for the (likely) smokers. The main effect and the interaction term have to be summed to obtain the treatment effect on net welfare for likely smokers. We also include the smoke propensity $p$ (smoke) directly to control for its partial correlation with life satisfaction. However, we do not interpret the coefficient for this variable, as causality potentially runs in both directions.

In order to take into account that the variable capturing the propensity to smoke is an estimated regressor, we implement a non-parametric bootstrap resampling procedure to obtain unbiased estimates of the standard errors. This procedure resamples on the first stage (the regressions that are used to predict the imputed propensities) as well as on the second stage (the regressions that use the imputed propensities to estimate the policies' impact on life satisfaction). We further sample (with replacement) from the countries and regions instead of the individual observations to take into account that the observations are potentially correlated within our clusters. The bootstrapped standard errors are based on 500 replications over both steps.

Table 2 reports the results for the extended specification. Based on column I, there might be - if anything - a positive effect of smoking bans on the life satisfaction of people with high smoking propensities. However, this effect is imprecisely estimated. In contrast, the effect of higher cigarette prices depends systematically on an individual's propensity to smoke. The life satisfaction of people with a predicted smoking propensity of zero is not statistically significantly affected by changes in cigarette prices. However, for people with a high propensity to smoke, higher cigarette prices are related to systematically lower levels of subjective well-being. To obtain the net effect of higher cigarette prices on likely smokers, the coefficients for the main effect and for the interaction term have to be combined. In column II, the linear combination of the two variables is reported. For a propensity of one, a fifty-percent price increase amounts to a reduction in life satisfaction of 0.09 points (i.e., $\ln (1.5) \times(0.027+-0.257))$. An individual's propensity to smoke is, on average, negatively correlated with reported satisfaction with life. As the variable for cigarette prices is mean-adjusted, the coefficient of -0.27 for the propensity to smoke indicates that for average cigarette prices, people with a propensity to smoke that is equal to one report, on average, a 0.27 points lower satisfaction with life than people with a propensity equal to zero.

In column III, we report the results of a more flexible form of the interaction between the propensity to smoke and the two tobacco control policies than in column I where a linear relationship is imposed. We assign each observation based on the smoke propensity in ascending order to one of four quartiles and include interaction terms with the variables, smoking ban, and, cigarette prices. This allows us to estimate a separate level effect or slope coefficient for every quartile of the propensity to smoke. The results suggest that people with a higher propensity to smoke fare better than people in the lowest quartile when a smoking ban is introduced. However, the effects for all quartiles reported in column III and column IV are statistically not significantly different from zero. For cigarette prices, the negative effect increases monotonically 
with ascending propensity to smoke. For the top quartile, the linear combination results in a negative partial correlation of -0.091 . For a fifty-percent price increase, this implies a reduction of reported satisfaction with life of 0.04 points.

In sum, the analysis for people with different propensities to smoke does not reveal statistically significant differential effects of smoking bans. In contrast, the results show that the overall negative effect of higher cigarette prices on life satisfaction of Table 1 is driven by the negative well-being consequences for the people with a high smoking propensity.

Table 2: Differential effects with regard to individuals' propensity to smoke

\begin{tabular}{|c|c|c|c|c|}
\hline & I & $\begin{array}{r}\mathrm{II} \\
\mathrm{ME} / \mathrm{LC}^{a}\end{array}$ & III & $\begin{array}{r}\mathrm{IV} \\
\mathrm{ME} / \mathrm{LC}^{a}\end{array}$ \\
\hline Smoking ban & $\begin{array}{l}-0.002 \\
(-0.06)\end{array}$ & $\begin{array}{l}-0.002 \\
(-0.06)\end{array}$ & $\begin{array}{l}-0.002 \\
(-0.08)\end{array}$ & $\begin{array}{l}-0.002 \\
(-0.08)\end{array}$ \\
\hline Ban x p(smoker) & $\begin{array}{r}0.060 \\
(0.93)\end{array}$ & $\begin{array}{c}0.058 \\
(1.20)\end{array}$ & & \\
\hline $\mathrm{q} 2($ smoker $) \mathrm{x}$ ban & & & $\begin{array}{c}0.019 \\
(1.08)\end{array}$ & $\begin{array}{l}0.017 \\
(0.86)\end{array}$ \\
\hline q3(smoker) x ban & & & $\begin{array}{c}0.030 \\
(1.47)\end{array}$ & $\begin{array}{r}0.028 \\
(1.34)\end{array}$ \\
\hline $\mathrm{q} 4$ (smoker) $\mathrm{x}$ ban & & & $\begin{array}{r}0.024 \\
(0.89) \\
\end{array}$ & $\begin{array}{r}0.022 \\
(0.85) \\
\end{array}$ \\
\hline $\ln$ (cigarette price) & $\begin{array}{r}0.027 \\
(0.58)\end{array}$ & $\begin{array}{r}0.027 \\
(0.58)\end{array}$ & $\begin{array}{l}0.015 \\
(0.31)\end{array}$ & $\begin{array}{c}0.015 \\
(0.31)\end{array}$ \\
\hline Price x p(smoker) & $\begin{array}{l}-0.257^{\text {*** }} \\
(-3.16)\end{array}$ & $\begin{array}{l}-0.229^{* * *} \\
(-2.52)\end{array}$ & & \\
\hline q2(smoker) x price & & & $\begin{array}{l}-0.058^{* *} \\
(-2.49)\end{array}$ & $\begin{array}{l}-0.043 \\
(-0.81)\end{array}$ \\
\hline q3(smoker) x price & & & $\begin{array}{l}-0.102^{* * *} \\
(-3.28)\end{array}$ & $\begin{array}{l}-0.086 \\
(-1.52)\end{array}$ \\
\hline $\mathrm{q} 4$ (smoker) x price & & & $\begin{array}{l}-0.107^{* * *} \\
(-3.27)\end{array}$ & $\begin{array}{l}-0.091 \\
(-1.54) \\
\end{array}$ \\
\hline $\mathrm{p}$ (smoker) & $\begin{array}{l}-0.270^{* * *} \\
(-3.15)\end{array}$ & $\begin{array}{l}-0.270^{* * *} \\
(-3.15)\end{array}$ & & \\
\hline q2(smoker) & & & $\begin{array}{l}-0.007 \\
(-0.66)\end{array}$ & $\begin{array}{l}-0.007 \\
(-0.66)\end{array}$ \\
\hline q3(smoker) & & & $\begin{array}{l}-0.031^{* *} \\
(-1.98)\end{array}$ & $\begin{array}{l}-0.031^{* *} \\
(-1.98)\end{array}$ \\
\hline q4(smoker) & & & $\begin{array}{l}-0.069^{* * *} \\
(-3.43)\end{array}$ & $\begin{array}{l}-0.069^{* * *} \\
(-3.43)\end{array}$ \\
\hline No. of observations & 629,930 & 629,930 & 629,930 & 629,930 \\
\hline No. of clusters & 40 & 40 & 40 & 40 \\
\hline $\mathrm{R}^{2}$ & 0.22 & 0.22 & 0.22 & 0.22 \\
\hline
\end{tabular}

Notes: OLS estimations. T-values in parentheses (z-values for linear combinations). Bootstrapped standard errors (500 replications over both steps) are clustered on the country/region level. All regressions control for individual characteristics, macroeconomic variables, other tobacco control measures, beer tax, country/region and survey wave fixed effects and linear as well as quadratic country-specific time trends. $\ln$ (cigarette price) is mean-adjusted. In columns III and IV, the reference category refers to people in the lowest quartile of the propensity to smoke (q1(smoker)).

a) Marginal effects (ME) for main effects. Linear combinations (LC) of the main (policy) effect with interaction effects of the interaction terms.

Significance levels: $* .05<p<.1, * * .01<p<.05, * * *<.01$. 


\subsection{Robustness Analysis: Specifications Similar to Gruber and Mullainathan (2005)}

The negative effect of higher cigarette prices for people with a high propensity to smoke is the exact opposite of the prominent previous finding in Gruber and Mullainathan (2005). A possible explanation for the differing results might be an omitted variable bias in the specifications used by these authors. They do not control for the prevalence of smoking bans and other tobacco control policies that might be positively correlated with tobacco taxes. Another reason might be that we use a slightly different specification of the regression equation. In order to assess the robustness of our results, we estimate a series of additional regressions adopting their specification details and present the results in Table 3 .

Table 3: Robustness analysis: Specifications similar to Gruber and Mullainathan (2005)

\begin{tabular}{|c|c|c|c|c|c|c|c|}
\hline Dependent variable & $\begin{array}{r}\mathrm{I} \\
\text { OLS } \\
\text { Life sat }\end{array}$ & $\begin{array}{r}\text { II } \\
2 \text { SLS } \\
\text { Life sat }\end{array}$ & $\begin{array}{r}\text { III } \\
\text { OLS } \\
\text { Not sat }\end{array}$ & $\begin{array}{r}\text { IV } \\
\text { OLS } \\
\text { Not sat }\end{array}$ & $\begin{array}{r}\mathrm{V} \\
\mathrm{OLS} \\
\text { Not sat }\end{array}$ & $\begin{array}{r}\mathrm{VI} \\
\text { OLS } \\
\text { Life sat }\end{array}$ & $\begin{array}{r}\text { VII } \\
\text { OLS } \\
\text { Life sat }\end{array}$ \\
\hline Smoking ban & $\begin{array}{c}0.000 \\
(0.02)\end{array}$ & $\begin{array}{l}-0.010 \\
(-0.27)\end{array}$ & $\begin{array}{c}-0.003 \\
(-0.41)\end{array}$ & & & & \\
\hline Ban x p(smoker) & $\begin{array}{r}0.050 \\
(0.73)\end{array}$ & $\begin{array}{r}0.086 \\
(0.87)\end{array}$ & $\begin{array}{r}0.006 \\
(0.35)\end{array}$ & & & & \\
\hline $\ln ($ total taxes $)$ & $\begin{array}{l}-0.005 \\
(-0.11)\end{array}$ & & $\begin{array}{l}0.019^{*} \\
(1.79)\end{array}$ & $\begin{array}{l}0.018^{*} \\
(1.84)\end{array}$ & & & \\
\hline $\ln (\operatorname{tax}) \times \mathrm{p}($ smoker $)$ & $\begin{array}{l}-0.203^{* * *} \\
(-2.88)\end{array}$ & & $\begin{array}{r}0.010 \\
(0.79)\end{array}$ & $\begin{array}{r}0.011 \\
(1.03)\end{array}$ & & & \\
\hline $\ln ($ cigarette prices $)$ & & $\begin{array}{r}0.028 \\
(0.28)\end{array}$ & & & & & \\
\hline $\ln ($ price $) \times \mathrm{p}($ smoker $)$ & & $\begin{array}{l}-0.323^{*} \\
(-1.78)\end{array}$ & & & & & \\
\hline Total taxes & & & & & $\begin{array}{c}0.004 \\
(1.17)\end{array}$ & $\begin{array}{c}0.012 \\
(0.85)\end{array}$ & $\begin{array}{l}-0.012 \\
(-0.74)\end{array}$ \\
\hline Tax x p(smoker) & & & & & $\begin{array}{c}0.004 \\
(0.61)\end{array}$ & $\begin{array}{l}-0.092^{* * *} \\
(-3.36)\end{array}$ & $\begin{array}{l}-0.061^{* * *} \\
(-2.79)\end{array}$ \\
\hline $\mathrm{p}$ (smoker) & $\begin{array}{l}-0.265^{* * *} \\
(-3.06)\end{array}$ & $\begin{array}{l}-0.286^{* * *} \\
(-3.08)\end{array}$ & $\begin{array}{l}0.046^{* * *} \\
(3.29)\end{array}$ & $\begin{array}{l}0.037^{* * *} \\
(2.77)\end{array}$ & $\begin{array}{l}0.159^{* * *} \\
(3.95)\end{array}$ & $\begin{array}{l}-1.037^{* * *} \\
(-5.52)\end{array}$ & $\begin{array}{l}-0.116 \\
(-1.40)\end{array}$ \\
\hline No. of obse & 629,930 & 629,930 & 629,930 & 629,930 & 629,930 & 629,930 & 629,930 \\
\hline No. of clusters & 40 & 40 & 40 & 40 & 40 & 40 & 40 \\
\hline $\mathrm{R}^{2}$ & 0.22 & 0.22 & 0.05 & 0.05 & 0.05 & 0.22 & 0.22 \\
\hline
\end{tabular}

Notes: OLS estimations in columns I and III to VII. 2SLS in column II with specific taxes as an instrument for cigarette prices. T-values in parentheses (z-values for linear combinations). Bootstrapped standard errors (500 replications over both steps) are clustered on the country/region level. All regressions control for individual characteristics, macroeconomic variables, country/region and survey-wave fixed effects and linear as well as quadratic country-specific time trends. Estimations I to IV also include other tobacco control measures and the beer tax. "Life sat" refers to the four-point scale, "Not sat" indicates that the dependent variable is 1 if people report the lowest level of subjective well-being (and 0 otherwise). Significance levels: $* .05<p<.1, * * .01<p<.05, * * *<.01$.

In column I of Table 3, we use real cigarette taxes per pack instead of real cigarette prices at purchasing-power parities. The estimates indicate that likely smokers also report lower life satisfaction if total cigarette taxes are higher. The linear combination of the main effect for taxes and the interaction effect for likely smokers is -0.208 ( $\mathrm{z}$-value $=-2.57$ ), which is almost identical 
to the results in column II of Table2. To assess the effect of price variation due to taxes, we apply an IV estimation approach with specific cigarette taxes as an instrument for cigarette prices in column II. This provides identification solely from tax-induced price movements. The negative partial correlation between prices and life satisfaction for likely smokers persists 9 Columns III to $\mathrm{V}$ focus on the reporting of the lowest level of subjective well-being; i.e., that people are not at all satisfied with their lives. People with a high propensity to smoke are not less likely to report not being at all satisfied with their life with higher cigarette taxes. This holds independently of whether we control for the presence of smoking bans. It also holds when total taxes per pack of 20 cigarettes are included in absolute terms, when the propensity to smoke is estimated without separating the sample between men and women and the smoking bans, and when the cigarette taxes, the beer taxes, and the measure for other tobacco control policies are not taken into account in column V. However, the positive correlation with unhappiness is less precisely measured. If the same specification is applied to analyze the variation over the full scale of reported life satisfaction in column VI, higher total taxes economically and statistically significantly reduce the life satisfaction of likely smokers. Finally, we test the sensitivity of our results by applying a similar year-wise imputation strategy for the propensity to smoke as performed in Gruber and Mullainathan (2005). We test the robustness of our results by applying an imputation strategy for the propensity to smoke that is as similar to theirs as possible. We estimate eight separate regressions for the years with information about smoking. For these years, we use the respective coefficients to impute the propensity to smoke. For the other years, we impute the propensity to smoke based on the coefficients from the two closest years for which we have the smoking information (weighted by the inverse of the distance in years). Column VII reveals that the negative effect of higher taxes on likely smokers is robust to this alternative imputation strategy.

Overall, the robustness checks show systematically different results for Europe compared to the ones for the United States and Canada. No obvious explanation is suggested by our analysis, and we can only speculate about possible reasons. For example, the prevalence of smoking is, on average, about ten percentage points higher in Europe than in the United States and Canada, and people hold systematically different beliefs about the health consequences of smoking (Cutler and Glaeser 2009). With smoking being potentially more stigmatized in the United States than in Europe, there might be positive well-being effects for people who smoke less or quit due to higher prices there, but not in Europe.

\footnotetext{
${ }^{9}$ The first-stage regression for the 2SLS estimation in column II reveals a highly significant positive partial correlation of the specific tax as well as its interaction with the propensity to smoke with the instrumented cigarette price. The effect of $\ln$ (specific taxes) on $\ln$ (cigarette price) is 0.121 ( $\mathrm{t}$-value $=2.17$ ) with Shea's Partial R-squared of 0.127 and an F-statistic of 3.48 (p-value=0.041), and the effect of $\ln (\operatorname{tax})^{*} p$ (smoker) on $\ln \left(\right.$ price) ${ }^{*} p($ smoker) is 0.226 (t-value $=5.00)$ with Shea's Partial R-squared of 0.413 and an F-statistic of 14.4 ( $\mathrm{p}$-value=0.000).
} 


\section{Tobacco Control Policies as Self-Binding Mechanisms}

Whether tobacco control policies serve as a self-control device for smokers is difficult to assess even with data on subjective well-being. The effect of smoking bans turned out not to be statistically significantly positive for likely smokers in Section 3.3 , and higher cigarette prices are even sizeably negatively correlated with the life satisfaction of people in this group. These results reflect average effects over all likely smokers. However, the prediction of a beneficial effect from restrictions does apply to people with limited willpower. In order to test the policies' effects for people who likely suffer from limited willpower, we analyze how likely smokers who recently tried but failed to quit smoking are affected by anti-smoking policies. The primary idea is to take failed attempts to quit smoking as an indication of limited willpower.

\subsection{Different Predictions of Behavioral Economic Models}

A focus on the group of smokers with potentially limited self-control allows us to explore not only whether likely "wannabe quitters" are affected differently than smokers who have not recently tried to stop smoking, but also whether the effects differ between smoking bans and cigarette prices. In order to understand any differential predictions, we briefly sketch the alternative perspectives in behavioral economic models.

O'Donoghue and Rabin (1999) and Gruber and Köszegi (2001, 2004) model self-control problems in terms of a person's conflicting short- and long-term preferences. Applied to their framework, individuals plan to smoke less in the long run, but when it comes to act, they fail to follow their plan. Under such circumstances, smoking bans as well as higher cigarette prices might serve as self-control devices, as they increase the costs of smoking. In turn, this reduces the need to rely on willpower and helps to adhere to a time-consistent consumption plan. Smoking bans and high cigarette prices can thus enhance the welfare of people with limited willpower 10

In the model of Bernheim and Rangel (2004), individuals operate either in a "hot" or a "cold" decision-making mode. In the hot state, people are in a dysfunctional mode in which they have no self-control and thus always consume the addictive good, irrespective of underlying preferences. In the cold state, in contrast, decisions follow long-term plans. Within this approach, smoking bans can help smokers to smoke less by reducing the occurrence of cues that bring them into a hot state and trigger smoking. For instance, seeing someone smoke a cigarette in a pub could be a cue that would entice the observer to smoke, and where self-restraint would demand substantial willpower. A smoking ban might break this link and facilitate time-consistent decision-making. In contrast, higher cigarette prices do not serve as a self-control device in such a direct way, because there is no price elasticity in the hot state. This applies as long as, first, cigarettes are affordable for an individual and, second, higher cigarette prices do not decrease the level of

\footnotetext{
${ }^{10}$ The theoretical prediction of positive welfare effects for these self-control devices relies on the interpretation that the long-term preferences serve as the welfare standard. With our approach, we rely on an (ex post) judgment of the overall consumption experience. The analysis of ex post life satisfaction judgments leaves it to the people how they weigh short-term consumption utility and, for example, the fulfillment of long-term consumption plans.
} 
addiction to a sufficient extent in the long run due to reduced smoking in the cold state. Similar conclusions follow from the model presented by Gul and Pesendorfer (2001), where smokers experience direct disutility from being tempted. This disutility can be at least partially avoided if smoking bans are in place, because this policy measure excludes the possibility of smoking inside the restaurant, bar or workplace from the set of options. With cigarette taxes, this cannot be achieved directly, at least in the short run. In the long run, lower levels of smoking due to higher cigarette prices might indirectly reduce the number of cues as well, for example, when smokers see fewer people smoking in public spaces. We will further discuss the potential of the two policies to reduce cues in Section 4.4 .

In sum, depending on the way we model time inconsistency in smokers' consumption behavior, different predictions for the welfare consequences of anti-smoking policies emerge. In a first attempt to empirically discriminate between the models' predictions, we analyze whether likely smokers who recently tried but failed to quit smoking, are differently affected by the introduction of smoking bans compared to an increase in cigarette prices.

\subsection{Differential Effects on Smokers Who Want to Quit Smoking (Marginal Smokers)}

Information on people's attempts to cease smoking is from EB surveys in 2006 and 2009. In these surveys, current smokers are asked whether they tried to give up smoking within the last twelve months. Individuals who tried to give up smoking, but failed, potentially suffer from self-control problems to the extent that they benefit marginally more than other categories of smokers from the nudge of the policies. We choose a neutral term and refer to them as marginal smokers.

We categorize every individual as either being a current smoker with no recent attempt to quit, a non-smoker or a marginal smoker. In our data, about 30 percent of all the smokers are such marginal smokers. We again apply a two-step approach to impute propensities for being a nonsmoker, a current smoker or a marginal smoker in our main dataset. In a first step, we estimate a multinomial logit model that we use in a second step to predict the respective propensities 11 Every individual has probability values for each of the three possible statuses that sum up to one. Their propensities thus show the relative likelihood of being either a non-smoker, a smoker or a marginal smoker. Again, we use these propensities to estimate differential effects of smoking bans and cigarette prices on people's life satisfaction.

Table 4 presents the results. Column I shows the estimated coefficients for simple interaction terms of the tobacco control policies with the particular propensities, and column II reports the respective marginal effects and values for the linear combinations. The estimated effects suggest, first, that smoking bans do not affect non-smokers, reduce the life satisfaction of people who are likely smokers (and who have not recently tried to cease smoking), but substantially increase the life satisfaction of marginal smokers. Second, the estimated effects suggest that higher cigarette

\footnotetext{
${ }^{11}$ The estimation results of the multinomial logit model are reported in Table A.6. Figure A.4 in the Appendix shows the distribution of the predicted propensities to be a non-smoker, a smoker or a marginal smoker.
} 
prices do not affect non-smokers, but reduce the life satisfaction of likely smokers, and even more so, that of marginal smokers. However, this interpretation has to be treated with caution as the marginal effects and the values for the linear combinations refer to out-of-sample predictions, i.e., they indicate the effect for a propensity of one for a particular status, while being zero for the other two statuses. These combinations do not occur in the data.

Table 4: Differential effects on smokers who want to quit smoking (marginal smokers)

\begin{tabular}{|c|c|c|c|c|}
\hline & $\mathrm{I}$ & $\begin{array}{r}\mathrm{II} \\
\mathrm{ME} / \mathrm{LC}^{a}\end{array}$ & III & $\begin{array}{r}\mathrm{IV} \\
\mathrm{ME} / \mathrm{LC}^{a}\end{array}$ \\
\hline Smoking ban ${ }^{b}$ & $\begin{array}{l}-0.000 \\
(-0.01)\end{array}$ & $\begin{array}{l}-0.000 \\
(-0.01)\end{array}$ & $\begin{array}{l}-0.019 \\
(-0.80)\end{array}$ & $\begin{array}{l}-0.019 \\
(-0.80)\end{array}$ \\
\hline Ban $x$ p $\left(\right.$ smoker $\left.^{c}\right)$ & $\begin{array}{l}-0.097 \\
(-1.26)\end{array}$ & $\begin{array}{l}-0.097 \\
(-1.38)\end{array}$ & & \\
\hline Ban x p(marginal smoker $\left.{ }^{c}\right)$ & $\begin{array}{l}0.335^{* *} \\
(2.02)\end{array}$ & $\begin{array}{l}0.335^{* *} \\
(2.11)\end{array}$ & & \\
\hline $\mathrm{q} 4$ (smoker) $\mathrm{x}$ ban & & & $\begin{array}{l}0.043^{*} \\
(1.75)\end{array}$ & $\begin{array}{r}0.024 \\
(1.07)\end{array}$ \\
\hline q4(marginal smoker) $\mathrm{x}$ ban & & & $\begin{array}{l}0.105^{* * *} \\
(3.20)\end{array}$ & $\begin{array}{l}0.086^{* * *} \\
(2.69)\end{array}$ \\
\hline $\mathrm{q} 4($ smoker + marginal $) \times$ ban & & & $\begin{array}{r}0.033 \\
(1.01)\end{array}$ & $\begin{array}{l}0.014 \\
(0.44)\end{array}$ \\
\hline Other $\mathrm{x}$ ban & & & $\begin{array}{l}0.041^{* *} \\
(2.28)\end{array}$ & $\begin{array}{r}0.022 \\
(1.06)\end{array}$ \\
\hline $\ln ($ cigarette price $)$ & $\begin{array}{r}0.010 \\
(0.19)\end{array}$ & $\begin{array}{r}0.010 \\
(0.19)\end{array}$ & $\begin{array}{c}0.014 \\
(0.29)\end{array}$ & $\begin{array}{c}0.014 \\
(0.29)\end{array}$ \\
\hline Price $\mathrm{x}$ p(smoker $)$ & $\begin{array}{r}-0.090 \\
(-0.94)\end{array}$ & $\begin{array}{l}-0.080 \\
(-0.78)\end{array}$ & & \\
\hline Price x p(marginal smoker $)$ & $\begin{array}{l}-0.429 * * \\
(-2.52)\end{array}$ & $\begin{array}{l}-0.419^{* *} \\
(-2.36)\end{array}$ & & \\
\hline $\mathrm{q} 4($ smoker $) \times$ price & & & $\begin{array}{l}-0.094^{* * *} \\
(-3.13)\end{array}$ & $\begin{array}{l}-0.080 \\
(-1.51)\end{array}$ \\
\hline $\mathrm{q} 4($ marginal smoker $) \times$ price & & & $\begin{array}{l}-0.111^{* * *} \\
(-2.60)\end{array}$ & $\begin{array}{l}-0.097 \\
(-1.51)\end{array}$ \\
\hline $\mathrm{q} 4($ smoker + marginal $) \times$ price & & & $\begin{array}{l}-0.121^{* * *} \\
(-3.06)\end{array}$ & $\begin{array}{l}-0.107^{*} \\
(-1.85)\end{array}$ \\
\hline Other $\mathrm{x}$ price & & & $\begin{array}{l}-0.075^{* * *} \\
(-2.65)\end{array}$ & $\begin{array}{l}-0.061 \\
(-1.15)\end{array}$ \\
\hline No. of observations & 629,930 & 629,930 & 629,930 & 629,930 \\
\hline No. of clusters & 40 & 40 & 40 & 40 \\
\hline $\mathrm{R}^{2}$ & 0.22 & 0.22 & 0.22 & 0.22 \\
\hline
\end{tabular}

Notes: OLS estimations. T-values in parentheses (z-values for linear combinations). Bootstrapped standard errors (500 replications over both steps) are clustered on the country/region level. All regressions control for individual characteristics, macroeconomic variables, other tobacco control measures, beer tax, country/region and survey-wave fixed effects as well as linear and quadratic country-specific time trends. $\ln$ (cigarette price) is mean-adjusted. All specifications also include the main effects for smokers, non-smokers and marginal smokers.

a) Marginal effects (ME) for main effects. Linear combinations (LC) of main (policy) effect with interaction effects of interaction terms.

b) The reference category refers to people with a high propensity to be non-smokers (top quartile).

c) Propensity to be a smoker is for smokers who have not tried to quit smoking, while the propensity to be a marginal smoker refers to smokers who tried to stop smoking.

Significance levels: $* .05<p<.1, * * .01<p<.05, * * *<.01$. 
In order to attain meaningful values for the policy effects on subjective well-being, we define separate groups of people who are characterized by large propensities in one of the three dimensions. This approach also overcomes the linearity assumption in specifications with simple interaction terms. For the specification in column III, we determine the people who are in the top quartile with regard to their propensity to smoke, as being either a marginal smoker or a non-smoker. As we try to identify the people in each country who are most likely to suffer from reduced willpower when it comes to smoking, we build the quartiles separately for every country. The remaining individuals are in the category others. As there is a partial overlap between the top quartiles of smokers and marginal smokers, the respective individuals are assigned a separate group (q4(smoker + marginal)). Based on this grouping, interaction terms with the tobacco control policies are included in the estimation, whereby the top quartile of non-smokers is left out and forms the reference group.

The estimation results in column III and the reported marginal effects and values for the linear combinations in column IV reveal systematic differences in how the groups are affected by smoking bans and cigarette prices. For people in the reference group (i.e., likely non-smokers), a small negative correlation between the introduction of a smoking ban and subjective well-being is measured. The life satisfaction of likely smokers (who have not recently tried to cease smoking) is slightly positively correlated with the introduction of a smoking ban. There is, however, a significant difference for smokers who have recently tried to give up smoking. The introduction of a smoking ban is related to a statistically significant 0.09 points increase in their reported satisfaction with life.

Differential effects are also observed for cigarette prices. Smokers, marginal smokers as well as people who simultaneously belong to the top quartiles of the propensity to be either a smoker or a marginal smoker are similarly negatively affected by higher cigarette prices. For likely non-smokers, higher cigarette prices are not correlated with their life satisfaction. These results suggest that the negative effect of higher prices on smokers' well-being also holds for smokers with limited willpower, while this latter group is positively affected by smoking bans. Figure 1 shows a graphical representation of the net-effects for the different groups.

\subsection{Robustness Analysis: Trends in Subjective Well-Being}

Before we further interpret the findings in Section 4.4, we investigate the robustness of the results reported in Table 4. In particular, we address the possibility that the heterogeneity in the effects of tobacco policies on people with different smoking statuses picks up differential trends in these people's well-being. There is, however, no simple test to exclude this alternative explanation, as there might well be substantive lead effects to smoking bans. People might react once the bans are announced. But more importantly, any mandated smoking restriction might be implemented in firms ahead of time.

To approach the issue, we first include lead terms for the particular top quartiles that are equal to the smoking ban variable for the year before the introduction of the ban, and zero otherwise. We present the result of this strategy in Table 5. The results in column I with the respective 
Figure 1: Net effects of bans and higher prices for non-smokers, smokers and people who want to quit smoking (marginal smokers)

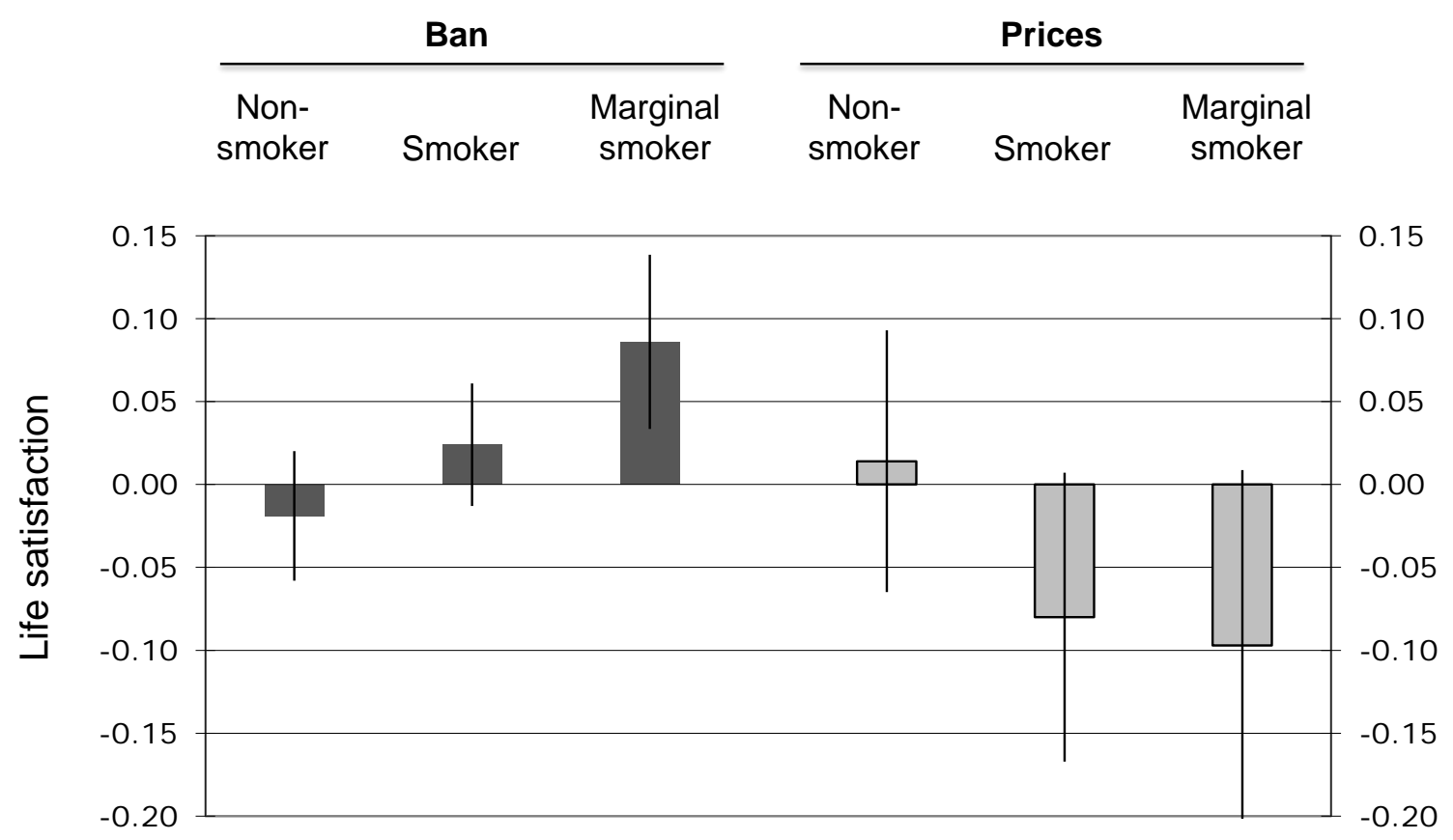

Notes: Effect sizes and 90 percent confidence intervals are based on the marginal effects and linear combinations from column IV in Table 4.

marginal effects and linear combinations in column II are very similar to the estimates presented in Table 4. Again, relative to non-smokers, marginal smokers experience an increase in subjective well-being with smoking bans. The respective marginal effect is 0.088 (z-value $=2.37$ ), while it amounts to 0.032 ( $\mathrm{z}$-value $=0.81$ ) during the lead phase.

Second, to control for potential underlying group-specific trends, we allow for a very flexible development of life satisfaction over time for the differentiated groups by including countryspecific time trends for all of them. The results of this flexible specification in the columns III and IV suggest that the statistically weakly positive lead effect of smoking bans for marginal smokers in column I is not robust. In contrast, the size of the well-being gain of marginal smokers remains considerable, although it is less precisely estimated. The linear combination in column IV which reflects the absolute increase in life satisfaction relative to the reference period (more than one year before the introduction of a smoking ban) is 0.049 (z-value=1.12); and the effect size relative to the life satisfaction of marginal smokers during the lead phase is estimated to be 0.063 ( $\mathrm{z}$-value=1.76). The differential results for cigarette prices across people of alternative smoking statuses remain similar to the results in Table 4. 
Table 5: Differential effects on marginal smokers: Robustness checks for lead effects and group-specific time trends

\begin{tabular}{|c|c|c|c|c|}
\hline & I & $\begin{array}{r}\mathrm{II} \\
\mathrm{ME} / \mathrm{LC}^{a}\end{array}$ & III & $\begin{array}{r}\mathrm{IV} \\
\mathrm{ME} / \mathrm{LC}^{a}\end{array}$ \\
\hline Smoking ban & $\begin{array}{l}-0.023 \\
(-0.72)\end{array}$ & $\begin{array}{l}-0.023 \\
(-0.72)\end{array}$ & $\begin{array}{r}0.005 \\
(0.19)\end{array}$ & $\begin{array}{r}0.005 \\
(0.19)\end{array}$ \\
\hline $\mathrm{q} 4($ smoker $) \mathrm{x}$ ban & $\begin{array}{l}0.044^{*} \\
(1.70)\end{array}$ & $\begin{array}{r}0.021 \\
(0.76)\end{array}$ & $\begin{array}{r}0.010 \\
(0.34)\end{array}$ & $\begin{array}{r}0.016 \\
(0.48)\end{array}$ \\
\hline q4(marginal smoker) $\mathrm{x}$ ban & $\begin{array}{l}0.111^{* * *} \\
(3.22)\end{array}$ & $\begin{array}{l}0.088^{* *} \\
(2.37)\end{array}$ & $\begin{array}{r}0.044 \\
(1.20)\end{array}$ & $\begin{array}{r}0.049 \\
(1.12)\end{array}$ \\
\hline $\mathrm{q} 4($ smoker + marginal $) \times$ ban & $\begin{array}{r}0.037 \\
(1.07)\end{array}$ & $\begin{array}{r}0.014 \\
(0.37)\end{array}$ & $\begin{array}{r}0.014 \\
(0.34)\end{array}$ & $\begin{array}{r}0.019 \\
(0.42)\end{array}$ \\
\hline Other $\mathrm{x}$ ban & $\begin{array}{l}0.046^{* *} \\
(2.50)\end{array}$ & $\begin{array}{r}0.024 \\
(0.83) \\
\end{array}$ & $\begin{array}{r}0.001 \\
(0.07) \\
\end{array}$ & $\begin{array}{r}0.007 \\
(0.24) \\
\end{array}$ \\
\hline Lead ban & $\begin{array}{l}-0.037 \\
(-1.35)\end{array}$ & $\begin{array}{l}-0.037 \\
(-1.35)\end{array}$ & $\begin{array}{l}-0.014 \\
(-0.61)\end{array}$ & $\begin{array}{l}-0.014 \\
(-0.61)\end{array}$ \\
\hline Lead q4(smoker) $\mathrm{x}$ ban & $\begin{array}{r}0.014 \\
(0.45)\end{array}$ & $\begin{array}{l}-0.023 \\
(-0.96)\end{array}$ & $\begin{array}{r}0.003 \\
(0.10)\end{array}$ & $\begin{array}{l}-0.011 \\
(-0.43)\end{array}$ \\
\hline Lead q4(marginal smoker) $\mathrm{x}$ ban & $\begin{array}{r}0.069 \\
(1.55)\end{array}$ & $\begin{array}{r}0.032 \\
(0.81)\end{array}$ & $\begin{array}{r}0.000 \\
(0.00)\end{array}$ & $\begin{array}{l}-0.014 \\
(-0.36)\end{array}$ \\
\hline Lead $\mathrm{q} 4($ smoker + marginal $) \mathrm{x}$ ban & $\begin{array}{r}0.040 \\
(0.86)\end{array}$ & $\begin{array}{r}0.003 \\
(0.07)\end{array}$ & $\begin{array}{r}0.014 \\
(0.31)\end{array}$ & $\begin{array}{r}0.000 \\
(0.01)\end{array}$ \\
\hline Lead other $\mathrm{x}$ ban & $\begin{array}{l}0.058^{* *} \\
(2.26)\end{array}$ & $\begin{array}{r}0.021 \\
(0.97)\end{array}$ & $\begin{array}{r}0.023 \\
(1.04)\end{array}$ & $\begin{array}{r}0.009 \\
(0.44)\end{array}$ \\
\hline $\ln ($ cigarette price $)$ & $\begin{array}{r}0.016 \\
(0.32)\end{array}$ & $\begin{array}{r}0.016 \\
(0.32)\end{array}$ & $\begin{array}{l}-0.018 \\
(-0.38)\end{array}$ & $\begin{array}{l}-0.018 \\
(-0.38)\end{array}$ \\
\hline $\mathrm{q} 4($ smoker $) \times$ price & $\begin{array}{l}-0.095 * * * \\
(-3.11)\end{array}$ & $\begin{array}{l}-0.079 \\
(-1.44)\end{array}$ & $\begin{array}{l}-0.025 \\
(-0.56)\end{array}$ & $\begin{array}{l}-0.042 \\
(-0.69)\end{array}$ \\
\hline $\mathrm{q} 4$ (marginal smoker) $\mathrm{x}$ price & $\begin{array}{l}-0.113^{* * *} \\
(-2.65)\end{array}$ & $\begin{array}{l}-0.097 \\
(-1.50)\end{array}$ & $\begin{array}{l}-0.060 \\
(-1.15)\end{array}$ & $\begin{array}{l}-0.078 \\
(-1.16)\end{array}$ \\
\hline $\mathrm{q} 4($ smoker + marginal $) \mathrm{x}$ price & $\begin{array}{l}-0.122^{* * *} \\
(-3.10)\end{array}$ & $\begin{array}{l}-0.106^{*} \\
(-3.10)\end{array}$ & $\begin{array}{l}-0.092 \\
(-1.41)\end{array}$ & $\begin{array}{l}-0.110 \\
(-1.55)\end{array}$ \\
\hline Other $\mathrm{x}$ price & $\begin{array}{l}-0.077^{* * *} \\
(-2.73)\end{array}$ & $\begin{array}{l}-0.061^{* * *} \\
(-1.14)\end{array}$ & $\begin{array}{l}-0.025 \\
(-0.77) \\
\end{array}$ & $\begin{array}{l}-0.043 \\
(-0.79) \\
\end{array}$ \\
\hline $\begin{array}{l}\mathrm{q} 4 \text { (smoking statuses) } \\
\quad \mathrm{x} \text { country-spec. time trends }\end{array}$ & No & No & Yes & Yes \\
\hline No. of observations & 629,930 & 629,930 & 629,930 & 629,930 \\
\hline No. of clusters & 40 & 40 & 40 & 40 \\
\hline $\mathrm{R}^{2}$ & 0.22 & 0.22 & 0.22 & 0.22 \\
\hline
\end{tabular}

Notes: OLS estimations. T-values in parentheses (z-values for linear combinations). Bootstrapped standard errors (500 replications over both steps) are clustered on the country/region level. All regressions control for individual characteristics, macroeconomic variables, other tobacco control measures, beer tax, country/region and survey wave fixed effects and linear as well as quadratic country-specific time trends. $\ln$ (cigarette price) is mean-adjusted. All specifications also include the main effects for smokers, non-smokers and marginal smokers.

a) Marginal effects (ME) for main effects. Linear combinations (LC) of main (policy) effect with interaction effects of interaction terms.

b) The reference category refers to people with a high propensity to be non-smokers (top quartile).

c) Propensity to be a smoker is for smokers who have not tried to quit smoking, while the propensity to be a marginal smoker refers to smokers who tried to stop smoking.

Significance levels: ${ }^{*} .05<p<.1,{ }^{* *} .01<p<.05,{ }^{* * *}<.01$.

In Table 6, we pursue three additional strategies to address the potential influence of underlying trends. First, we capture short-term effects by restricting the sample to observations within a fixed time window around the country-specific implementation date of the ban. Column I shows 
a specification where we use only those observations in a country or region that are surveyed within three years before or after the implementation, and column II presents the respective marginal effects and linear combinations. Comparable to the results in Tables 4 and 5 , we observe a net effect for marginal smokers of $0.062(\mathrm{z}$-value $=2.08)$ when a ban is introduced. For the reduced sample, effects similar to Tables 4 and 5 are also estimated for cigarette prices 12

Table 6: Differential effects on marginal smokers: Further robustness checks

\begin{tabular}{|c|c|c|c|c|c|}
\hline & $\mathrm{I}$ & $\begin{array}{r}\mathrm{II} \\
\mathrm{ME} / \mathrm{LC}^{a}\end{array}$ & III & $\begin{array}{r}\mathrm{IV} \\
\mathrm{ME} / \mathrm{LC}^{a}\end{array}$ & $\mathrm{~V}$ \\
\hline Smoking ban ${ }^{b}$ & $\begin{array}{r}0.037 \\
(1.35)\end{array}$ & $\begin{array}{r}0.037 \\
(1.35)\end{array}$ & $\begin{array}{l}-0.018 \\
(-0.76)\end{array}$ & $\begin{array}{l}-0.018 \\
(-0.76)\end{array}$ & \\
\hline $\mathrm{q} 4\left(\right.$ smoker $\left.^{c}\right) \times$ ban & $\begin{array}{l}0.006 \\
(0.23)\end{array}$ & $\begin{array}{r}0.043 \\
(1.46)\end{array}$ & $\begin{array}{l}0.042^{*} \\
(1.73)\end{array}$ & $\begin{array}{r}0.025 \\
(1.07)\end{array}$ & $\begin{array}{r}0.037 \\
(1.49)\end{array}$ \\
\hline $\mathrm{q} 4\left(\right.$ marginal smoker $\left.{ }^{c}\right) \times$ ban & $\begin{array}{r}0.025 \\
(0.81)\end{array}$ & $\begin{array}{l}0.062^{* *} \\
(2.08)\end{array}$ & $\begin{array}{l}0.101^{* * *} \\
(3.19)\end{array}$ & $\begin{array}{l}0.083^{* * *} \\
(2.71)\end{array}$ & $\begin{array}{l}0.105^{* * * *} \\
(3.19)\end{array}$ \\
\hline $\mathrm{q} 4($ smoker + marginal $) \times$ ban & $\begin{array}{l}-0.017 \\
(-0.47)\end{array}$ & $\begin{array}{r}0.020 \\
(0.62)\end{array}$ & $\begin{array}{r}0.036 \\
(1.12)\end{array}$ & $\begin{array}{r}0.018 \\
(0.57)\end{array}$ & $\begin{array}{r}0.034 \\
(1.05)\end{array}$ \\
\hline Other $\mathrm{x}$ ban & $\begin{array}{l}-0.014 \\
(-0.66)\end{array}$ & $\begin{array}{r}0.023 \\
(1.01)\end{array}$ & $\begin{array}{l}0.039^{* *} \\
(2.18)\end{array}$ & $\begin{array}{r}0.021 \\
(1.02)\end{array}$ & $\begin{array}{l}0.041^{* *} \\
(2.38)\end{array}$ \\
\hline $\ln ($ cigarette prices $)$ & $\begin{array}{l}-0.002 \\
(-0.04)\end{array}$ & $\begin{array}{l}-0.002 \\
(-0.04)\end{array}$ & $\begin{array}{l}-0.011 \\
(-0.22)\end{array}$ & $\begin{array}{l}-0.011 \\
(-0.22)\end{array}$ & \\
\hline $\mathrm{q} 4($ smoker $) \times$ price & $\begin{array}{l}-0.091^{* *} \\
(-2.47)\end{array}$ & $\begin{array}{l}-0.093 \\
(-1.56)\end{array}$ & $\begin{array}{l}-0.049 \\
(-1.46)\end{array}$ & $\begin{array}{l}-0.061 \\
(-1.14)\end{array}$ & $\begin{array}{l}-0.087^{* * *} \\
(-2.81)\end{array}$ \\
\hline q4(marginal smoker) $x$ price & $\begin{array}{l}-0.163^{* * *} \\
(-3.87)\end{array}$ & $\begin{array}{l}-0.165^{* *} \\
(-2.50)\end{array}$ & $\begin{array}{l}-0.059 \\
(-1.37)\end{array}$ & $\begin{array}{l}-0.070 \\
(-1.12)\end{array}$ & $\begin{array}{l}-0.114^{* * *} \\
(-2.68)\end{array}$ \\
\hline $\mathrm{q} 4($ smoker + marginal $) \times$ price & $\begin{array}{l}-0.114^{* *} \\
(-2.56)\end{array}$ & $\begin{array}{l}-0.117^{*} \\
(-1.87)\end{array}$ & $\begin{array}{l}-0.106^{* *} \\
(-2.10)\end{array}$ & $\begin{array}{l}-0.117^{*} \\
(-1.92)\end{array}$ & $\begin{array}{l}-0.117^{* * *} \\
(-2.95)\end{array}$ \\
\hline Other $\mathrm{x}$ price & $\begin{array}{l}-0.093^{* * *} \\
(-2.94)\end{array}$ & $\begin{array}{l}-0.095 \\
(-1.64) \\
\end{array}$ & $\begin{array}{l}-0.035 \\
(-1.35) \\
\end{array}$ & $\begin{array}{l}-0.046 \\
(-0.87) \\
\end{array}$ & $\begin{array}{l}-0.072^{* *} \\
(-2.53)\end{array}$ \\
\hline $\begin{array}{l}\text { Sample reduced to } 3 \text { years } \\
\text { before \& after ban intro } \\
\mathrm{q} 4 \text { (smoking statuses) }\end{array}$ & Yes & Yes & No & No & No \\
\hline $\begin{array}{l}\text { x macroeconomic variables } \\
\text { Fixed effects: }\end{array}$ & No & No & Yes & Yes & No \\
\hline country/region $\mathrm{x}$ survey wave & No & No & No & No & Yes \\
\hline No. of observations & 271,188 & 271,188 & 629,930 & 629,930 & 629,930 \\
\hline No. of clusters & 40 & 40 & 40 & 40 & 40 \\
\hline $\mathrm{R}^{2}$ & 0.26 & 0.26 & 0.22 & 0.22 & 0.22 \\
\hline
\end{tabular}

Notes: OLS estimations. T-values in parentheses (z-values for linear combinations). Bootstrapped standard errors (500 replications over both steps) are clustered on the country/region level. All regressions control for individual characteristics, macroeconomic variables, other tobacco control measures and for the beer tax. Specifications I-IV control for linear and quadratic country-specific time trends. $\ln$ (cigarette price) is mean-adjusted. All specifications also include the main effects for smokers, non-smokers and marginal smokers.

a) Marginal effects (ME) for main effects. Linear combinations (LC) of main (policy) effect with interaction effects of interaction terms.

b) The reference category refers to people with a high propensity to be non-smokers (top quartile).

c) Propensity to be a smoker is for smokers who have not tried to quit smoking, while the propensity to be a marginal smoker refers to smokers who tried to stop smoking.

Significance levels: $* .05<p<.1, * * .01<p<.05, * * *<.01$.

\footnotetext{
${ }^{12}$ When we vary the range of included observations between one and ten years before and after the ban, the biggest net effect for marginal smokers amounts to 0.075 (z-value $=1.73$, one year before and after the ban), while the smallest effect is 0.047 ( $\mathrm{z}$-value $=1.72$, five years before and after the ban).
} 
Second, any underlying trend for the different groups might also be driven by differential exposure to macroeconomic conditions. The specifications in columns III and IV take this concern into account. For every group, different partial correlations with the macroeconomic variables as well as the other tobacco control policies and the beer taxes are considered by including interaction terms. Again, a positive differential effect for marginal smokers is estimated. The respective interaction term is 0.101 ( $\mathrm{t}$-value $=3.19)$, amounting to a total effect of $0.083(\mathrm{z}$-value $=2.71$ ).

Third, in our most flexible specification, we allow a specific level-effect for observations from any country/region in a particular survey wave, i.e., we include country/region x wave specific fixed effects. The focus is thus on the change in the difference between smokers or marginal smokers vis-à-vis non-smokers when smoking bans are introduced. Due to the flexible specification, the main effect for the variable smoking ban can no longer be identified. This exercise produces a differential effect of the ban for marginal smokers of 0.105 ( $t$-value=3.19), i.e., any difference between marginal smokers and non-smokers increases in favor of the marginal smokers by 0.105 units on the four-point life satisfaction scale if a smoking ban is introduced. As for the previous robustness checks, the differential effects for cigarette prices across groups remain very similar to the baseline findings in Table 4 .

\subsection{Discussion of the Evidence for Models of Cue-Triggered Decision-Making}

Overall, the results can be interpreted as evidence that smoking bans can serve as a self-control device for individuals with limited willpower, while higher cigarette prices do not appear to be useful for this purpose. In turn, this evidence supports models that build on processes of cue-triggered decision-making. They predict that smoking bans, but not cigarette taxes, help to reduce overconsumption for given levels of addiction. In this brief discussion, we (i) set the central finding of our study in relation to the results of other recent studies, (ii) relate the argument of cues to peer effects, and (iii) present some circumstantial evidence that smoking bans appear to be effective in reducing exposure to second-hand smoke.

There is some related evidence for the view that with limited willpower, smokers who want to cease smoking display a demand for self-control devices. Based on survey data from Taiwan, Kan (2007) shows that a smoker's intention to quit smoking has a positive effect on his or her support for smoking bans or for an increase in the cigarette excise tax. Note that traditionally cigarette prices are lower in Taiwan than in many other countries. Hersch (2005) comes to the same conclusion in support of clean-air laws in the United States. Additionally, he studies the effect for smokers who have tried to quit smoking in the past, but have failed, and who plan to try quitting again. This group favors smoking bans more than smokers who plan to quit smoking for the first time. In another study for the United States, Fletcher et al. (2009) analyze differences in cigarette tax elasticities for different levels of self-control. They find evidence in a sample of adolescents that low levels of self-control are strongly related to low responsiveness to prices.

The concept of cues is a rather generic one to circumscribe environmental conditions that trigger specific emotions and might well include social context. Smoking bans are interventions that 
change various conditions for consuming tobacco, including social interaction. Related peer effects might thus be a mechanism underlying our empirical findings. First, with smoking bans, smokers often consume locally separated from non-smokers, and can less directly express their invitations to join in. People might thus be less exposed to peer pressure. Second, they are also less exposed to seeing friends with a cigarette, a situation that usually serves as a strong cue that triggers smoking. Indeed with smoking, the strongest cues might be social ones, i.e., being exposed to other people smoking in one's environment. There is some empirical evidence that supports this argument. For example, Niaura et al. (1992) discuss the role of smoking cues in interactions between smokers. They report that smokers' blood pressure increased during a role play where the counterparty manipulated an unlit cigarette or smoked a cigarette in view of the subjects. They additionally cite studies which find that exposure to tobacco accessories results in a shorter period of latency before consuming the first cigarette, an increase in the number of cigarettes smoked, and an increase in puff-duration among smokers after a short period of abstinence from cigarettes.

In the light of this reasoning, smoking bans might reduce cues, because smokers see fewer people smoking around them. Additionally, smokers might experience less pressure from their friends in a restaurant or a pub, as people are not allowed to smoke inside. Both channels make smokers who find it difficult to abstain from smoking due to limited willpower better off. We are not able to disentangle these intertwined mechanisms in our empirical analysis. However, we can at least test whether there is evidence for the main mechanism involving cues, i.e., that people are less often exposed to smoking in offices, restaurants and bars if smoking bans are in place (and that any such effect is smaller for high cigarette prices).

In order to provide some circumstantial evidence that smoking bans are more effective in reducing the number of tempting situations than higher cigarette prices, we conduct an additional empirical analysis. The key idea is that we take reported passive smoking to approximate the extent to which people are exposed to cues. Whether bans and prices have an effect on passive smoking thus offers some indication of whether people are more or less exposed to cues. Specifically, a finding that smoking bans have a stronger effect on passive smoking than higher cigarette prices could be considered as evidence for the argument that bans reduce cues more effectively than higher prices.

To perform the empirical test, we make use of a Eurobarometer survey wave from 2006. In this survey, respondents are asked how long they are exposed to tobacco smoke on a daily basis in different places. They were able to reply in four categories, namely "never or almost never"; "less than one hour"; "one to five hours" or "more than five hours". Using this information, we build an indicator variable that is equal to zero if people are never or almost never exposed to passive smoking in the respective places, and equal to one otherwise. We can use this information as our dependent variable and regress it on our policy variables together with the controls. We concentrate our analysis on the responses with regard to, first, indoor workplaces or offices, and, second, restaurants, bars or pubs, as the smoking bans across Europe particularly restrict smoking in those places. As we are only able to exploit a cross-section for 2006, we cannot include country-specific fixed effects. The effect shown for the smoking bans thus indicates 
the difference in the probability of being exposed to passive smoking in countries that have a smoking ban and countries that have no smoking bans implemented in 2006 ${ }^{13}$ However, we additionally control for the country- and region-specific rate of smoking that could be correlated with the smoking policies, as well as with the probability of being exposed to passive smoking.

Table 7: Impact of tobacco control policies on the exposure to passive smoking in indoor workplaces and restaurants/bars in 2006

\begin{tabular}{|c|c|c|c|c|}
\hline & $\begin{array}{r}\text { Office } \\
\text { I }\end{array}$ & $\begin{array}{r}\text { Rest./bar } \\
\text { II }\end{array}$ & $\begin{array}{r}\text { Office } \\
\text { III }\end{array}$ & $\begin{array}{r}\text { Rest./bar } \\
\text { IV }\end{array}$ \\
\hline Smoking ban & $\begin{array}{l}-0.086 * * \\
(-2.62)\end{array}$ & $\begin{array}{l}-0.292^{* * *} \\
(-3.54)\end{array}$ & $\begin{array}{l}-0.052^{* *} \\
(-2.14)\end{array}$ & $\begin{array}{l}-0.272^{* * *} \\
(-3.87)\end{array}$ \\
\hline Ban x smoker & & & $\begin{array}{l}-0.116^{* *} \\
(-2.64)\end{array}$ & $\begin{array}{l}-0.068 \\
(-1.08)\end{array}$ \\
\hline $\ln ($ cigarette price $)$ & $\begin{array}{r}0.028 \\
(1.34)\end{array}$ & $\begin{array}{r}0.096 \\
(1.48)\end{array}$ & $\begin{array}{l}0.041^{*} \\
(1.83)\end{array}$ & $\begin{array}{l}0.102^{*} \\
(1.74)\end{array}$ \\
\hline Price x smoker & & & $\begin{array}{l}-0.049^{* * *} \\
(-2.97)\end{array}$ & $\begin{array}{l}-0.023 \\
(-0.45)\end{array}$ \\
\hline Smoker & & & $\begin{array}{l}0.409^{* * *} \\
(4.80)\end{array}$ & $\begin{array}{r}0.245 \\
(0.92)\end{array}$ \\
\hline Rate of smoking & $\begin{array}{l}0.688^{* * *} \\
(5.16)\end{array}$ & $\begin{array}{c}0.394 \\
(0.76)\end{array}$ & $\begin{array}{l}0.614^{* * *} \\
(4.93)\end{array}$ & $\begin{array}{l}0.326 \\
(0.62)\end{array}$ \\
\hline Other tobacco policies & $\begin{array}{l}-0.004^{* * *} \\
(-2.79)\end{array}$ & $\begin{array}{c}-0.010 \\
(-1.65)\end{array}$ & $\begin{array}{l}-0.004^{* * *} \\
(-2.81)\end{array}$ & $\begin{array}{r}-0.010 \\
(-1.63)\end{array}$ \\
\hline $\ln ($ beer tax $)$ & $\begin{array}{l}-0.024^{* *} \\
(-2.60)\end{array}$ & $\begin{array}{l}-0.067 \\
(-1.59)\end{array}$ & $\begin{array}{l}-0.022^{* *} \\
(-2.37)\end{array}$ & $\begin{array}{c}-0.066 \\
(-1.53)\end{array}$ \\
\hline $\ln ($ GDP per capita) & $\begin{array}{l}-0.125^{* * *} \\
(-3.54)\end{array}$ & $\begin{array}{r}0.070 \\
(0.68)\end{array}$ & $\begin{array}{l}-0.118^{* * *} \\
(-3.32)\end{array}$ & $\begin{array}{r}0.076 \\
(0.73)\end{array}$ \\
\hline Unemployment rate & $\begin{array}{l}-0.006^{* *} \\
(-2.47)\end{array}$ & $\begin{array}{l}-0.001 \\
(-0.07)\end{array}$ & $\begin{array}{l}-0.005^{* *} \\
(-2.16)\end{array}$ & $\begin{array}{l}-0.000 \\
(-0.02)\end{array}$ \\
\hline Inflation rate & $\begin{array}{l}-0.024^{* *} \\
(-2.26)\end{array}$ & $\begin{array}{r}0.012 \\
(0.44)\end{array}$ & $\begin{array}{l}-0.024 * * \\
(-2.23)\end{array}$ & $\begin{array}{r}0.012 \\
(0.44)\end{array}$ \\
\hline No. of observations & 21,118 & 21,022 & 21,118 & 21,022 \\
\hline No. of clusters & 40 & 40 & 40 & 40 \\
\hline $\mathrm{R}^{2}$ & 0.10 & 0.16 & 0.12 & 0.18 \\
\hline
\end{tabular}

Notes: Linear probability models. T-values in parentheses. Standard errors are clustered on the country/region level. All regressions control for individual characteristics.

Significance levels: $* .05<p<.1, * * .01<p<.05, * * *<.01$.

As columns I and II in Table 7 show, we find a negative partial correlation between smoking bans and passive smoking in indoor working places as well as in restaurants, bars and pubs. The effect is particularly strong for the latter, with a reduction in the probability of being exposed to passive smoking of almost 30 percentage points when smoking bans are implemented. For the exposure to different levels of cigarette prices, we do not find a statistically significant partial correlation with second-hand smoking. For likely smokers the linear combination of the coefficients amounts to -0.008 (p-value $=0.70)$ when they are at the office and to $0.079(\mathrm{p}$-value $=0.39)$ when they are in a restaurant or bar. Importantly for our argument, the negative effect of bans on passive

\footnotetext{
${ }^{13}$ Roughly half of the countries have implemented smoking bans before the respective interview dates, namely Belgium (workplace ban), Estonia (workplace ban), Ireland, Italy, Latvia, Luxembourg, Malta, the Netherlands (workplace ban), Spain, Sweden, and Scotland.
} 
smoking applies for smokers even more than for non-smokers. This is indicated by the negative interaction terms of the smoking ban variable with being current smoker in columns III and IV. Together, these results provide circumstantial evidence that smoking bans are able to reduce the cues by means of reducing the number of people who smoke in close proximity to one another.

\section{Conclusions}

The public health debate on tobacco consumption is highly controversial. Some policy briefs are oriented towards solving an intervention problem to reduce smoking no matter what the cost. Other voices see recent developments in anti-smoking policy as modern witch-hunts and plea for the freedom of consumers. It is inherently difficult to assess whether someone who smokes less or gives up smoking because of some policy intervention is made better or worse off. Recent developments in the economic analysis of people's subjective well-being offer new opportunities to explore the effects of policies on people's welfare.

We assess the welfare consequences of tobacco control policies by analyzing information on individuals' satisfaction with life for more than half a million people in Europe. We concentrate on the introduction of smoking bans in the workplace and in the hospitality sector as well as on differences in cigarette prices that reflect variation in tobacco excise taxes to a large extent. We investigate 40 interventions that were implemented across European countries and regions, and apply an empirical strategy that concentrates on the variation in reported life satisfaction around a linear and quadratic country-specific time trend to identify potential policy effects.

Based on policy implementations spanning the last twenty years in Europe, we find that smoking bans, on average, slightly increase people's subjective well-being. However, not to a statistically significant degree. Higher cigarette prices are related to overall lower reported levels of satisfaction with life, ceteris paribus. The partial correlation is, however, measured with a large standard error. Still, the effect is economically meaningful (and corroborated by our differential analysis for people with different smoking propensities). For a fifty-percent price increase, we estimate a reduction in average life satisfaction of 0.04 points (on a four-point scale). This is more than one eighth of the effect of being unemployed rather than employed or equivalent to the effect of a 2.7 percentage points higher rate of unemployment on the population at large. Higher cigarette prices thus at least have overall negative short-term effects. When assessing the attractiveness of excise taxes as instruments of welfare and revenue policy, these short-term costs should be taken into account and balanced against any potential long-term effects that positively affect average subjective well-being. This might be through productive public expenditures or positive health and longevity effects. The traditional argument is that due to the price elasticity of smoking and the social multipliers involved in smoking behavior (see, e.g., Christakis and Fowler 2008), people smoke less with higher taxes, which in turn leads to a generally healthier population in the long run.

We further find that the negative effects of higher cigarette prices are concentrated on smokers. Non-smokers neither benefit nor suffer in terms of subjective well-being. This finding highlights 
the distributional consequences of tobacco taxation, as smoking is much more prevalent in poorer socio-economic groups. Tobacco taxation thus has a regressive component. In fact, the large negative effects of higher prices might well reflect income effects to some extent. For example, in our sample, the average real price per package of cigarettes in the most popular price class amounted to 3.45 euros in 2005 , with 75 percent of this being tax. In comparison, in 2005 the average legal real minimum wage per hour was about five euros in the same set of countries. For low income households, consumption expenditure on cigarettes therefore potentially erodes a substantial part of their budget.

Additionally, smoking bans turn out to be beneficial for smokers who would like to stop smoking (or not start again). For those smokers who are most likely to find themselves in a situation where they have recently tried to give up smoking but have relapsed, life satisfaction increases between 0.05 to 0.09 points with smoking bans (depending on the specification). This is evidence that supports the idea that smoking bans can serve as a self-control device. Interestingly, the same group of people do not benefit from higher cigarette prices. On the contrary, these people seem to suffer to the same extent as other smokers do who have not recently tried to stop. The negative effect of higher cigarette prices on smokers, particularly those who are likely to have self-control problems, runs counter to the prominent finding by Gruber and Mullainathan (2005) for the United States and Canada where positive effects of higher cigarette taxes on the well-being of smokers are identified.

The differential effects of alternative tobacco control policies on people who are likely to suffer from limited willpower provide some smoking-gun evidence in support of behavioral economic models of cue-triggered decision-making (Bernheim and Rangel 2004). These models emphasize the importance of situational cues and temptations and the limited effectiveness of prices as a self-control device when consumers are in a "hot" state.

We advocate to take the emerging research that integrates the analysis of peoples' reported subjective well-being into account for policy evaluations. This is particularly important with regard to policies that aim to internalize social costs or to help people make better decisions, what often is denoted as paternalistic. Complementary insights are possible when studying direct measures of individual welfare. 


\section{References}

Adda, J. and F. Cornaglia (2010). The Effect of Bans and Taxes on Passive Smoking. American Economic Journal: Applied Economics 2(1), 1-32.

Ai, C. and E. C. Norton (2003). Interaction Terms in Logit and Probit Models. Economics Letters 80(1), 123-129.

Anger, S., M. Kvasnicka, and T. Siedler (2011). One Last Puff? Public Smoking Bans and Smoking Behavior. Journal of Health Economics 30(3), 591-601.

Aufmuth, P. (2010). Rauchverbot in Deutschland. Available from: http://www. rauchverbot-deutschland.de (accessed 05.03.2011).

Becker, G. S. and K. M. Murphy (1988). A Theory of Rational Addiction. Journal of Political Economy 96(4), 675-700.

Benesch, C., B. S. Frey, and A. Stutzer (2010). TV Channels, Self-Control and Happiness. B.E. Journal of Economic Analysis \& Policy 10(1), 1635-1682.

Bernheim, B. D. and A. Rangel (2004). Addiction and Cue-Triggered Decision Processes. American Economic Review 94(5), 1558-1590.

Brodeur, A. (2013). Smoking, Income and Subjective Well-Being: Evidence from Smoking Bans. IZA Discussion Paper No. 7357. Bonn: IZA.

Carpenter, C., S. Postolek, and C. Warman (2011). Public-Place Smoking Laws and Exposure to Environmental Tobacco Smoke (ETS). American Economic Journal: Economic Policy 3(3), $35-61$.

Chaloupka, F. J., R. Peck, J. A. Tauras, X. Xu, and A. Yurekli (2010). Cigarette Excise Taxation: The Impact of Tax Structure on Prices, Revenues, and Cigarette Smoking. NBER Working Paper No. 16287. Cambridge MA: National Bureau of Economic Research.

Chaloupka, F. J. and K. E. Warner (2000). The Economics of Smoking. In A. J. Culyer and H. P. Newhouse (Eds.), Handbook of Health Economics, Volume 1, pp. 1539-1627. New York: Elsevier.

Christakis, N. A. and J. H. Fowler (2008). The Collective Dynamics of Smoking in a Large Social Network. New England Journal of Medicine 358(21), 2249-2258.

Cnossen, S. (2006). Tobacco Taxation in the European Union. FinanzArchiv 62(2), 305-322.

Cutler, D. M. and E. L. Glaeser (2009). Why Do Europeans Smoke More than Americans? In D. A. Wise (Ed.), Developments in the Economics of Aging, pp. 255-282. Chicago: University of Chicago Press.

European Commission (1990-2011a). Excise Duty Tables: Part II - Alcoholic Beverages. Brussels: European Commission.

European Commission (1990-2011b). Excise Duty Tables: Part III - Manufactured Tobacco. Brussels: European Commission. 
European Commission (2010). Implementation of Smoke-Free Laws in the EU: Measures by Member State - May 2010. Available from: http://ec.europa.eu/health/index\{_\}en. html (accessed 05.03.2011).

European Commission (2012). Eurobarameter. Brussels: European Commission.

European Network for Smoking Prevention (2010). European Trends Towards Smoke-Free Provisions, January 2011. Available from: http://www . ensp. org/node/70 (accessed 05.03.2011).

Fichtenberg, C. M. and S. A. Glantz (2002). Effect of Smoke-Free Workplaces on Smoking Behaviour: Systematic Review. British Medical Journal 325(7357), 188-194.

Fletcher, J. M., P. Deb, and J. L. Sindelar (2009). Tobacco Use, Taxation and Self Control in Adolescence. NBER Working Paper No. 15130. Cambridge MA: National Bureau of Economic Research.

Frey, B. S. and A. Stutzer (2002). What Can Economists Learn from Happiness Research? Journal of Economic Literature 40(2), 402-435.

Gruber, J. (2001). Tobacco at the Crossroads: The Past and Future of Smoking Regulation in the United States. Journal of Economic Perspectives 15(2), 193-212.

Gruber, J. and B. Kőszegi (2001). Is Addiction "Rational"? Theory and Evidence. Quarterly Journal of Economics 116(4), 1261-1303.

Gruber, J. and B. Kőszegi (2004). Tax Incidence when Individuals are Time-Inconsistent: The Case of Cigarette Excise Taxes. Journal of Public Economics 88(9-10), 1959-1987.

Gruber, J. H. and S. Mullainathan (2005). Do Cigarette Taxes Make Smokers Happier. Advances in Economic Analysis 83 Policy 5(1), 1-43.

Gul, F. and W. Pesendorfer (2001). Temptation and Self-Control. Econometrica 69(6), 14031435 .

Hersch, J. (2005). Smoking Restrictions as a Self-Control Mechanism. Journal of Risk and Uncertainty 31(1), 5-21.

Hopkins, D. P., S. Razi, K. D. Leeks, G. P. Kalra, S. K. Chattopadhyay, and R. E. Soler (2010). Smokefree Policies to Reduce Tobacco Use: A Systematic Review. American Journal of Preventive Medicine 38(2S), 275-289.

Hsee, C. K., Y. Rottenstreich, and A. Stutzer (2012). Suboptimal Choices and the Need for Experienced Individual Well-Being in Economic Analysis. International Journal of Happiness and Development 1(1), 63-85.

Joossens, L. and M. Raw (2006). The Tobacco Control Scale: A New Scale to Measure Country Activity. Tobacco Control 15(3), 247-253.

Joossens, L. and M. Raw (2007). Progress in Tobacco Control in 30 European Countries, 2005 to 2007. Swiss Cancer League: Berne. 
Joossens, L. and M. Raw (2011). The Tobacco Control Scale 2010 in Europe. Association of European Cancer Leagues: Brussels.

Kan, K. (2007). Cigarette Smoking and Self-Control. Journal of Health Economics 26(1), 61-81.

Köszegi, B. and M. Rabin (2008). Choices, Situations, and Happiness. Journal of Public Economics 92(8-9), 1821-1832.

Kuehnle, D. and C. Wunder (2013). The Effects of Smoking Bans on Self-Assessed Health: Evidence from Germany. SOEPpapers on Multidisciplinary Panel Data Research 586. DIW: Berlin.

Kvasnicka, M. (2010). Public Smoking Bans, Youth Access Laws, and Cigarette Sales at Vending Machines. Ruhr Economic Paper Nr. 173. Bochum: Ruhr-University.

Layard, R. (2005). Happiness: Lessons from a New Science. London: Penguin Books.

Leicester, A. and P. Levell (2013). Anti-Smoking Policies and Smoker Well-Being: Evidence from Britain. IFS Working Papers W13/13. London: Institute for Fiscal Studies.

Meyers, D. G., J. S. Neuberger, and J. He (2009). Cardiovascular Effect of Bans on Smoking in Public Places: A Systematic Review and Meta-Analysis. Journal of the American College of Cardiology 54(14), 1249-1255.

Niaura, R., D. B. Abrams, M. Pedraza, and P. M. Monti (1992). Smokers' Reactions to Interpersonal Interaction and Presentation of Smoking Cues. Addictive Behaviors 17(6), 557-566.

O'Donoghue, T. and M. Rabin (1999). Doing It Now or Later. American Economic Review 89(1), $103-124$.

Pell, J. P., S. Haw, S. Cobbe, D. E. Newby, A. C. H. Pell, C. Fischbacher, A. McConnachie, S. Pringle, D. Murdoch, F. Dunn, K. Oldroyd, P. MacIntyre, B. O'Rourke, and W. Borland (2008). Smoke-Free Legislation and Hospitalizations for Acute Coronary Syndrome. New England Journal of Medicine 359(5), 482-491.

Stutzer, A. (2009). Happiness When Temptation Overwhelms Willpower. In A. K. Dutt and B. Radcliff (Eds.), Happiness, Economics and Politics: Towards a Multi-Disciplinary Approach, pp. 97-126. Cheltenham UK: Edward Elgar Publishing.

Stutzer, A. and B. S. Frey (2010). Recent Advances in the Economics of Individual Subjective Well-Being. Social Research 77(2), 679-714.

Stutzer, A. and A. Meier (2015). Limited Self-Control, Obesity, and the Loss of Happiness. Forthcoming in Health Economics.

Tauras, J. A. (2006). Smoke-Free Air Laws, Cigarette Prices, and Adult Cigarette Demand. Economic Inquiry 44(2), 333-342.

Toshkov, D. (2013). Policy-Making Beyond Political Ideology: The Adoption of Smoking Bans in Europe. Public Administration 91(2), 448-468.

Viscusi, W. K. (1992). Smoking: Making the Risky Decision. New York: Oxford University Press. 


\section{Appendix}

Figure A.1: Real cigarette prices and real cigarette taxes (in 2005 Euros) per 1000 cigarettes
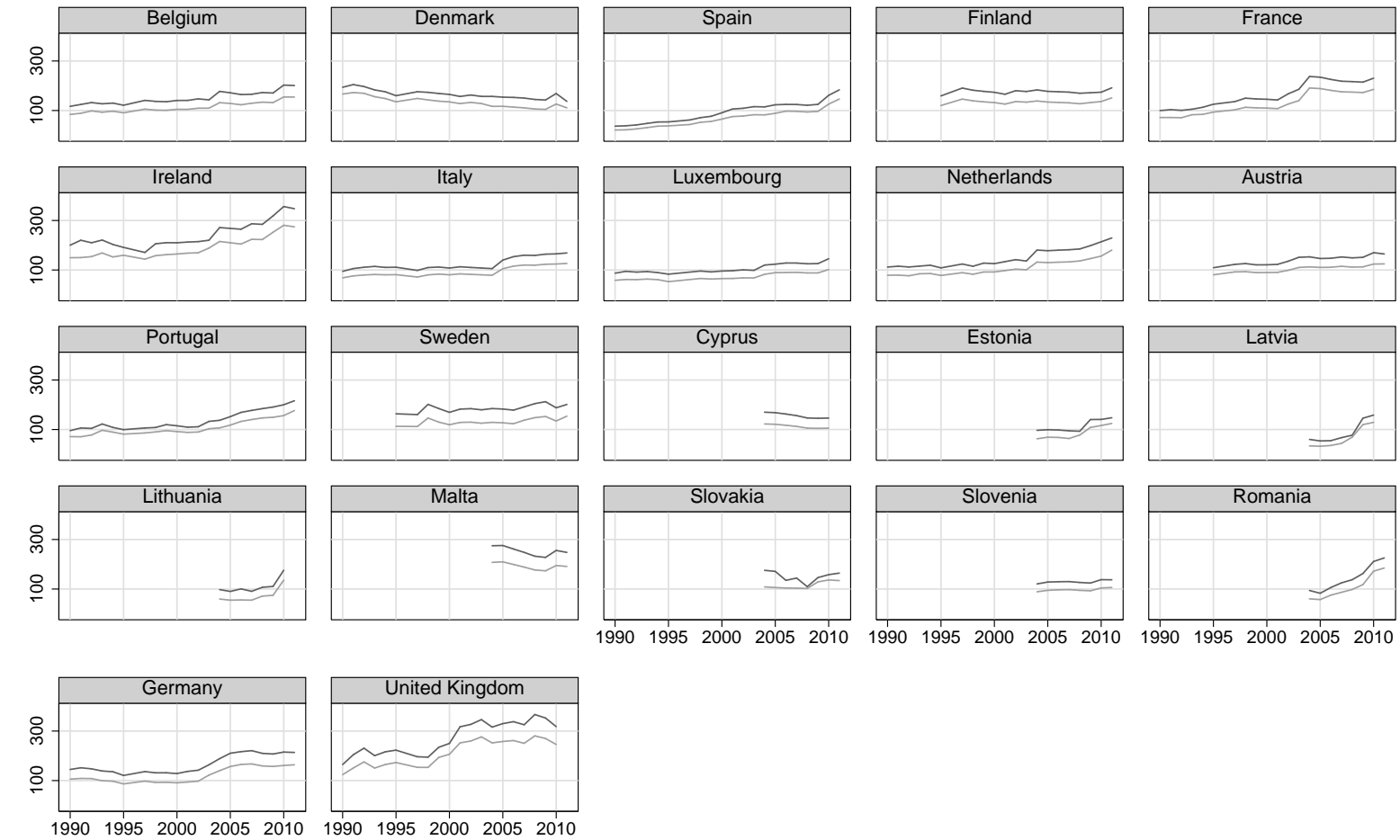

$\begin{array}{lllllllllllllll}1990 & 1995 & 2000 & 2005 & 2010 & 1990 & 1995 & 2000 & 2005 & 2010 & 1990 & 1995 & 2000 & 2005 & 2010\end{array}$

Cigarette prices

Total tax

Data sources: Own calculations based on the Excise Duty Tables provided by the European Commission (1990-2011a) and on the country-specific price level (source: see Table A.2) 
Table A.1: Descriptive statistics

\begin{tabular}{|c|c|c|c|c|}
\hline & Mean & Std. dev. & Min. & Max. \\
\hline \multicolumn{5}{|l|}{ Individual level } \\
\hline Life satisfaction & 3.048 & 0.742 & 1.000 & 4.000 \\
\hline Age & 45.892 & 18.218 & 15.000 & 99.000 \\
\hline Female & 0.535 & 0.499 & 0.000 & 1.000 \\
\hline Education up to age 17 & 0.252 & 0.434 & 0.000 & 1.000 \\
\hline Education up to age $18-21$ & 0.394 & 0.489 & 0.000 & 1.000 \\
\hline Education up to age 22 and more & 0.262 & 0.440 & 0.000 & 1.000 \\
\hline Student & 0.092 & 0.289 & 0.000 & 1.000 \\
\hline No fulltime education & 0.003 & 0.055 & 0.000 & 1.000 \\
\hline Married & 0.529 & 0.499 & 0.000 & 1.000 \\
\hline Single with partner & 0.081 & 0.272 & 0.000 & 1.000 \\
\hline Single & 0.218 & 0.413 & 0.000 & 1.000 \\
\hline Divorced & 0.072 & 0.259 & 0.000 & 1.000 \\
\hline Widowed & 0.090 & 0.287 & 0.000 & 1.000 \\
\hline Other & 0.009 & 0.095 & 0.000 & 1.000 \\
\hline No child in $\mathrm{HH}$ under age 15 & 0.605 & 0.489 & 0.000 & 1.000 \\
\hline One child in $\mathrm{HH}$ under age 15 & 0.131 & 0.337 & 0.000 & 1.000 \\
\hline Two children in $\mathrm{HH}$ under age 15 & 0.093 & 0.290 & 0.000 & 1.000 \\
\hline Three children in $\mathrm{HH}$ under age 15 & 0.026 & 0.159 & 0.000 & 1.000 \\
\hline Four children in $\mathrm{HH}$ under age 15 & 0.009 & 0.094 & 0.000 & 1.000 \\
\hline No info about children in $\mathrm{HH}$ & 0.137 & 0.344 & 0.000 & 1.000 \\
\hline Working & 0.497 & 0.500 & 0.000 & 1.000 \\
\hline Unemployed & 0.064 & 0.244 & 0.000 & 1.000 \\
\hline Out of labour force & 0.439 & 0.496 & 0.000 & 1.000 \\
\hline \multicolumn{5}{|l|}{ Country level } \\
\hline Smoking ban & 0.200 & 0.311 & 0.000 & 1.000 \\
\hline Cigarette prices & 162.123 & 60.843 & 36.700 & 366.919 \\
\hline $\ln$ (cigarette prices) & 5.018 & 0.384 & 3.603 & 5.905 \\
\hline Beer tax & 3.051 & 2.934 & 0.279 & 14.784 \\
\hline $\ln ($ beer tax $)$ & 0.732 & 0.859 & -1.276 & 2.694 \\
\hline Other tobacco policies & 20.678 & 4.996 & 8.000 & 27.000 \\
\hline GDP per capita & 23670.544 & 7241.468 & 7787.305 & 65864.922 \\
\hline $\ln ($ GDP per capita) & 10.028 & 0.303 & 8.960 & 11.095 \\
\hline Unemployment rate (in \%) & 8.200 & 3.827 & 1.600 & 21.600 \\
\hline Inflation rate (in \%) & 2.880 & 2.247 & -1.700 & 15.300 \\
\hline No. of observations & 629,930 & & & \\
\hline
\end{tabular}

Data sources: Individual-level data is from the Eurobarometer Survey Series. HH stands for household. For country-level data, see Tables 1 and A.3 and Figure A.1. 
Table A.2: Data sources

Individual-level data from Eurobarometer

Cumulated data from the Mannheim Trend File are extended by individual survey waves up to 2011 and variables are coded accordingly. Additional surveys included: 60.1; 62.0; 62.2; 63.4; $64.2 ; 65.2 ; 66.1 ; 67.2 ; 68.1 ; 69.2 ; 70.1 ; 71.1 ; 71.2 ; 71.3 ; 73.4 ; 74.2 ; 75.3$.

Smoking behavior

- Surveys: $34.1 ; 38.0 ; 41.0 ; 43.0 ; 58.2 ; 64.1 ; 66.2 ; 72.3$.

- Question and answers: Which of the following applies to yourself? 1. You smoke manufactured cigarettes; 2. You smoke roll-your-own cigarettes; 3. You smoke cigars or a pipe; 4. You used to smoke but you have stopped; 5 . You have never smoked.

Attempts to quit smoking

- Surveys: 66.2; 72.3 .

- Question and answers: Have you tried to give up smoking in the last 12 months (only current smokers)? 1. Yes, once; 2. Yes, between 2 and 5 times; 3. Yes, more than 5 times; 4. No.

Country level data

Gross domestic product

- Eurostat: epp.eurostat.ec.europa.eu (data file nama_aux_gph)

- World Bank: data.worldbank.org (for Ireland and Portugal)

Unemployment rate

- Eurostat: epp.eurostat.ec.europa.eu (data file une_rt_a)

- German Federal Employment Agency: statistik.arbeitsagentur.de (for German Laender)

- Welsh Government: statswales.wales.gov.uk (for UK regions)

Inflation rate

- Eurostat: epp.eurostat.ec.europa.eu (data file prc_hicp_aind)

- OECD: stats.oecd.org (for 1990 and for Sweden 1990-1995)

- European Central Bank: sdw.ecb.europa.eu (for EU-27)

Price level index

- Eurostat: epp.eurostat.ec.europa.eu (data file prc_ppp_ind)

- OECD: stats.oecd.org (for 1990-1994) 
Table A.3: Introduction dates of public smoking bans in 40 European countries and regions

\begin{tabular}{|c|c|c|c|c|}
\hline \multirow[b]{2}{*}{ Country } & \multicolumn{2}{|c|}{ Workplace ban } & \multicolumn{2}{|c|}{ Hospitality sector ban } \\
\hline & $\begin{array}{l}\text { Introduction } \\
\text { date }\end{array}$ & $\begin{array}{l}\text { Scope } \\
{[1-10]}\end{array}$ & $\begin{array}{l}\text { Introduction } \\
\text { date }\end{array}$ & $\begin{array}{l}\text { Scope } \\
{[1-8]}\end{array}$ \\
\hline Austria & 01.01 .09 & 2 & 01.07 .10 & 2 \\
\hline Belgium & 01.01 .06 & 6 & 01.01 .07 & 4 \\
\hline Cyprus (Republic of) & 01.01 .10 & 2 & 01.01 .10 & 6 \\
\hline Denmark & 15.08 .07 & 4 & 15.08 .07 & 4 \\
\hline Estonia & 04.06 .05 & 4 & 05.06 .07 & 6 \\
\hline Finland & 01.06 .07 & 8 & 01.06 .07 & 6 \\
\hline France & 01.02 .07 & 8 & 01.01 .08 & 6 \\
\hline \multicolumn{5}{|l|}{ Germany $^{a}$ (East): } \\
\hline Berlin & 01.01 .08 & 4 & 01.01 .08 & 4 \\
\hline Brandenburg & 01.01 .08 & 4 & 01.01 .08 & 4 \\
\hline Mecklenburg-West Pomerania & 01.01 .08 & 4 & 01.01 .08 & 4 \\
\hline Saxony & 01.02 .08 & 4 & 01.02 .08 & 4 \\
\hline Saxony-Anhalt & 01.01 .08 & 4 & 01.01 .08 & 4 \\
\hline Thuringia & 01.07 .08 & 4 & 01.07 .08 & 4 \\
\hline \multicolumn{5}{|l|}{ Germany (West): } \\
\hline Baden-Wurttemberg & 01.08 .07 & 4 & 01.08 .07 & 4 \\
\hline Bavaria & 01.01 .08 & 4 & 01.01 .08 & 4 \\
\hline Bremen & 01.01 .08 & 4 & 01.01 .08 & 4 \\
\hline Hamburg & 01.01 .08 & 4 & 01.01 .08 & 4 \\
\hline Hesse & 01.10 .07 & 4 & 01.10 .07 & 4 \\
\hline Lower Saxony & 01.08 .07 & 4 & 01.08 .07 & 4 \\
\hline North Rhine-Westphalia & 01.07 .08 & 4 & 01.07 .08 & 4 \\
\hline Rhineland-Palatinate & 15.02 .08 & 4 & 15.02 .08 & 4 \\
\hline Saarland & 01.02 .08 & 4 & 01.02 .08 & 4 \\
\hline Schleswig-Holstein & 01.01 .08 & 4 & 01.01 .08 & 4 \\
\hline Ireland & 29.03 .04 & 10 & 29.03 .04 & 8 \\
\hline Italy & 10.01 .05 & 8 & 10.01 .05 & 6 \\
\hline \multirow[t]{2}{*}{ Latvia } & 01.07 .06 & 4 & 01.07 .06 & 4 \\
\hline & & & 01.10 .10 & $8^{b}$ \\
\hline Lithuania & 01.01 .07 & 4 & 01.01 .07 & 6 \\
\hline Luxembourg & 05.09 .06 & 4 & 05.09 .06 & 4 \\
\hline Malta & 01.04 .05 & 8 & 01.04 .05 & 6 \\
\hline Netherlands & 01.01 .04 & 6 & 01.07 .08 & 4 \\
\hline Portugal & 01.01 .08 & 4 & 01.01 .08 & 4 \\
\hline Romania & 01.01 .09 & 2 & 01.01 .09 & 2 \\
\hline Slovakia & 01.04 .09 & 4 & 01.09 .09 & 4 \\
\hline Slovenia & 01.08 .07 & 6 & 01.08 .07 & 6 \\
\hline
\end{tabular}

(Continued on next page) 
Table A.3: (continued)

\begin{tabular}{lllll}
\hline Spain & 01.01 .06 & 10 & 01.01 .06 & 2 \\
Sweden & 01.06 .05 & 6 & 01.06 .05 & 6 \\
\hline United Kingdom: & & & & \\
Wales & 02.04 .07 & 10 & 02.04 .07 & 8 \\
Scotland & 01.03 .06 & 10 & 01.03 .06 & 8 \\
England & 01.07 .07 & 10 & 01.07 .07 & 8 \\
Northern Ireland & 30.04 .07 & 10 & 30.04 .07 & 8 \\
\hline
\end{tabular}

Notes: ${ }^{a)}$ According to Joossens and Raw (2007, 2011) tobacco control in workplaces in Germany became more restrictive between 2007 and 2010; i.e., the index of the Tobacco Control Scale increased from 2 to 4 . As there is no change in the federal law, we assume that the change occured parallel to the implementation of bans in the hospitality sector.

b) In Latvia the ban in the hospitality sector was tightened on May $1^{\text {st }}, 2010$.

Data sources: European countries and regions in the UK: European Commission (2010), European Network for Smoking Prevention (2010); German Laender: Aufmuth (2010), Kvasnicka (2010); Tobacco Control Scale: Joossens and Raw (2006, 2007, 2011). 
Table A.4: Smoking bans, cigarette prices and life satisfaction in 40 European countries and regions, 1990-2011: Full regression outputs

Dependent variable: Life satisfaction

\begin{tabular}{|c|c|c|c|c|c|}
\hline & I & II & III & IV & $\mathrm{V}$ \\
\hline Smoking ban & $\begin{array}{r}0.025 \\
(1.52)\end{array}$ & & $\begin{array}{r}0.022 \\
(1.36)\end{array}$ & $\begin{array}{r}0.026 \\
(1.36)\end{array}$ & $\begin{array}{r}0.016 \\
(0.92)\end{array}$ \\
\hline $\ln ($ cigarette price $)$ & & $\begin{array}{l}-0.099 * * * \\
(-2.81)\end{array}$ & $\begin{array}{l}-0.097^{* * * *} \\
(-2.74)\end{array}$ & $\begin{array}{l}-0.085^{* *} \\
(-2.08)\end{array}$ & $\begin{array}{l}-0.054 \\
(-1.13)\end{array}$ \\
\hline Other tobacco policies & & & & $\begin{array}{r}0.001 \\
(0.27)\end{array}$ & $\begin{array}{r}0.002 \\
(0.47)\end{array}$ \\
\hline $\ln ($ beer tax $)$ & & & & $\begin{array}{l}-0.042 \\
(-0.96)\end{array}$ & $\begin{array}{l}-0.028 \\
(-0.78)\end{array}$ \\
\hline $\ln ($ GDP per capita $)$ & & & & & $\begin{array}{l}-0.034 \\
(-0.17)\end{array}$ \\
\hline Unemployment rate & & & & & $\begin{array}{l}-0.008 \\
(-1.39)\end{array}$ \\
\hline Inflation rate & & & & & $\begin{array}{r}0.004 \\
(1.35)\end{array}$ \\
\hline Age & $\begin{array}{l}-0.021^{* * *} \\
(-13.11)\end{array}$ & $\begin{array}{l}-0.021^{* * *} \\
(-13.10)\end{array}$ & $\begin{array}{l}-0.021^{* * *} \\
(-13.10)\end{array}$ & $\begin{array}{l}-0.021^{* * *} \\
(-13.11)\end{array}$ & $\begin{array}{l}-0.021^{* * *} \\
(-13.11)\end{array}$ \\
\hline $\mathrm{Age}^{2} / 100$ & $\begin{array}{l}0.021^{* * *} \\
(14.26)\end{array}$ & $\begin{array}{l}0.021^{* * *} \\
(14.25)\end{array}$ & $\begin{array}{l}0.021^{* * * *} \\
(14.25)\end{array}$ & $\begin{array}{l}0.021^{* * * *} \\
(14.25)\end{array}$ & $\begin{array}{c}0.021^{\text {**** }} \\
(14.24)\end{array}$ \\
\hline Female & $\begin{array}{l}0.021 * * * \\
(3.17)\end{array}$ & $\begin{array}{l}0.021 * * * \\
(3.17)\end{array}$ & $\begin{array}{l}0.021^{* * *} \\
(3.18)\end{array}$ & $\begin{array}{l}0.021^{* * *} \\
(3.17)\end{array}$ & $\begin{array}{l}0.021^{* * * *} \\
(3.18)\end{array}$ \\
\hline $\begin{array}{c}\text { Education until less } \\
\text { than age } 15\end{array}$ & & & $\begin{array}{r}\text { Reference } \\
\text { category }\end{array}$ & & \\
\hline Education until age 15 & $\begin{array}{l}0.031^{* * *} \\
(2.73)\end{array}$ & $\begin{array}{l}0.031^{* * *} \\
(2.72)\end{array}$ & $\begin{array}{l}0.031^{* * *} \\
(2.72)\end{array}$ & $\begin{array}{l}0.031^{* * *} \\
(2.72)\end{array}$ & $\begin{array}{l}0.031^{* * * *} \\
(2.72)\end{array}$ \\
\hline Education until age 16 & $\begin{array}{l}0.043^{* * *} \\
(4.60)\end{array}$ & $\begin{array}{l}0.042^{* * *} \\
(4.59)\end{array}$ & $\begin{array}{l}0.043^{* * *} \\
(4.59)\end{array}$ & $\begin{array}{l}0.042^{* * *} \\
(4.58)\end{array}$ & $\begin{array}{l}0.042^{* * * *} \\
(4.57)\end{array}$ \\
\hline Education until age 17 & $\begin{array}{l}0.064^{* * *} \\
(5.72)\end{array}$ & $\begin{array}{l}0.064^{* * *} \\
(5.71)\end{array}$ & $\begin{array}{l}0.064^{* * *} \\
(5.71)\end{array}$ & $\begin{array}{l}0.064^{* * *} \\
(5.71)\end{array}$ & $\begin{array}{l}0.064^{* * *} \\
(5.71)\end{array}$ \\
\hline Education until age 18 & $\begin{array}{l}0.093^{* * *} \\
(7.56)\end{array}$ & $\begin{array}{l}0.093^{* * *} \\
(7.55)\end{array}$ & $\begin{array}{l}0.093^{* * *} \\
(7.55)\end{array}$ & $\begin{array}{l}0.093^{* * *} \\
(7.54)\end{array}$ & $\begin{array}{l}0.093^{* * * *} \\
(7.51)\end{array}$ \\
\hline Education until age 19 & $\begin{array}{l}0.116^{* * *} \\
(11.23)\end{array}$ & $\begin{array}{l}0.115^{* * * *} \\
(11.21)\end{array}$ & $\begin{array}{l}0.115^{* * * *} \\
(11.22)\end{array}$ & $\begin{array}{l}0.115^{* * * *} \\
(11.21)\end{array}$ & $\begin{array}{l}0.115^{* * *} \\
(11.21)\end{array}$ \\
\hline Education until age 20 & $\begin{array}{l}0.127^{* * *} \\
(13.57)\end{array}$ & $\begin{array}{l}0.127^{* * * *} \\
(13.56)\end{array}$ & $\begin{array}{l}0.127^{* * * *} \\
(13.57)\end{array}$ & $\begin{array}{l}0.127^{* * * *} \\
(13.56)\end{array}$ & $\begin{array}{l}0.127^{* * *} \\
(13.62)\end{array}$ \\
\hline Education until age 21 & $\begin{array}{l}0.144^{* * *} \\
(14.84)\end{array}$ & $\begin{array}{l}0.144^{* * *} \\
(14.81)\end{array}$ & $\begin{array}{l}0.144^{* * *} \\
(14.83)\end{array}$ & $\begin{array}{l}0.144^{* * *} \\
(14.82)\end{array}$ & $\begin{array}{l}0.144^{* * *} \\
(14.82)\end{array}$ \\
\hline Education until age $22+$ & $\begin{array}{c}0.156^{* * *} \\
(14.40)\end{array}$ & $\begin{array}{l}0.156^{* * *} \\
(14.39)\end{array}$ & $\begin{array}{l}0.156^{* * *} \\
(14.40)\end{array}$ & $\begin{array}{c}0.156^{* * *} \\
(14.39)\end{array}$ & $\begin{array}{l}0.156^{* * *} \\
(14.41)\end{array}$ \\
\hline Student & $\begin{array}{l}0.220^{* * *} \\
(14.77)\end{array}$ & $\begin{array}{l}0.220^{* * *} \\
(14.77)\end{array}$ & $\begin{array}{l}0.220^{* * *} \\
(14.81)\end{array}$ & $\begin{array}{l}0.220^{* * *} \\
(14.80)\end{array}$ & $\begin{array}{l}0.220^{* * *} \\
(14.85)\end{array}$ \\
\hline No fulltime education & $\begin{array}{l}-0.101^{* * *} \\
(-3.05)\end{array}$ & $\begin{array}{l}-0.102^{* * *} \\
(-3.04)\end{array}$ & $\begin{array}{l}-0.102^{* * *} \\
(-3.04)\end{array}$ & $\begin{array}{l}-0.101^{* * *} \\
(-3.06)\end{array}$ & $\begin{array}{l}-0.104^{* * *} \\
(-3.17)\end{array}$ \\
\hline Married & & & $\begin{array}{r}\text { Reference } \\
\text { category }\end{array}$ & & \\
\hline Single with partner & $\begin{array}{l}-0.084^{* * *} \\
(-17.53)\end{array}$ & $\begin{array}{l}-0.084^{* * *} \\
(-17.57)\end{array}$ & $\begin{array}{l}-0.084^{* * *} \\
(-17.56)\end{array}$ & $\begin{array}{l}-0.084^{* * *} \\
(-17.57)\end{array}$ & $\begin{array}{l}-0.084^{* * * *} \\
(-17.47)\end{array}$ \\
\hline Single & $\begin{array}{l}-0.155^{* * *} \\
(-13.05)\end{array}$ & $\begin{array}{l}-0.155^{* * *} \\
(-13.03)\end{array}$ & $\begin{array}{l}-0.155^{* * * *} \\
(-13.04)\end{array}$ & $\begin{array}{l}-0.155^{* * *} \\
(-13.05)\end{array}$ & $\begin{array}{l}-0.155^{* * * *} \\
(-13.02)\end{array}$ \\
\hline Divorced & $\begin{array}{l}-0.275^{* * *} \\
(-22.82)\end{array}$ & $\begin{array}{l}-0.275^{* * *} \\
(-22.83)\end{array}$ & $\begin{array}{l}-0.275^{* * *} \\
(-22.82)\end{array}$ & $\begin{array}{l}-0.275^{* * *} \\
(-22.80)\end{array}$ & $\begin{array}{l}-0.275^{* * *} \\
(-22.81)\end{array}$ \\
\hline Widowed & $\begin{array}{l}-0.208^{* * *} \\
(-17.95)\end{array}$ & $\begin{array}{l}-0.208^{* * *} \\
(-17.99)\end{array}$ & $\begin{array}{l}-0.208^{* * * *} \\
(-17.99)\end{array}$ & $\begin{array}{l}-0.208^{* * *} \\
(-17.95)\end{array}$ & $\begin{array}{l}-0.207^{* * * *} \\
(-17.98)\end{array}$ \\
\hline Other marital status & $\begin{array}{l}-0.106^{* * *} \\
(-4.02)\end{array}$ & $\begin{array}{l}-0.106^{* * *} \\
(-4.01)\end{array}$ & $\begin{array}{l}-0.106^{* * *} \\
(-4.02)\end{array}$ & $\begin{array}{l}-0.106^{* * *} \\
(-4.00)\end{array}$ & $\begin{array}{l}-0.107^{* * *} \\
(-4.03)\end{array}$ \\
\hline $\begin{array}{c}\text { No children in } \mathrm{HH} \\
\text { under age } 15\end{array}$ & & & $\begin{array}{r}\text { Reference } \\
\text { category }\end{array}$ & & \\
\hline $\begin{array}{r}\text { One child in } \mathrm{HH} \\
\text { under age } 15\end{array}$ & $\begin{array}{l}-0.011^{* *} \\
(-2.53)\end{array}$ & $\begin{array}{l}-0.011^{* *} \\
(-2.51)\end{array}$ & $\begin{array}{l}-0.011^{* *} \\
(-2.51)\end{array}$ & $\begin{array}{l}-0.011^{* *} \\
(-2.52)\end{array}$ & $\begin{array}{l}-0.011^{* *} \\
(-2.46)\end{array}$ \\
\hline
\end{tabular}


Table A.4: (continued)

\begin{tabular}{|c|c|c|c|c|c|}
\hline $\begin{array}{l}\text { Two children in } \mathrm{HH} \\
\text { under age } 15\end{array}$ & $\begin{array}{l}-0.008 \\
(-1.34)\end{array}$ & $\begin{array}{l}-0.008 \\
(-1.35)\end{array}$ & $\begin{array}{l}-0.008 \\
(-1.34)\end{array}$ & $\begin{array}{l}-0.008 \\
(-1.35)\end{array}$ & $\begin{array}{l}-0.008 \\
(-1.32)\end{array}$ \\
\hline Three children in $\mathrm{HH}$ & $-0.019^{*}$ & $-0.019^{*}$ & $-0.019^{*}$ & $-0.019^{*}$ & $-0.019^{*}$ \\
\hline under age 15 & $(-1.96)$ & $(-1.96)$ & $(-1.96)$ & $(-1.97)$ & $(-1.94)$ \\
\hline Four or more children in $\mathrm{HH}$ & $-0.041 * *$ & $-0.041^{* *}$ & $-0.041^{* *}$ & $-0.041^{* *}$ & $-0.041^{* *}$ \\
\hline under age 15 & $(-2.50)$ & $(-2.50)$ & $(-2.50)$ & $(-2.51)$ & $(-2.48)$ \\
\hline No info about children in $\mathrm{HH}$ & $\begin{array}{l}-0.011 \\
(-0.46)\end{array}$ & $\begin{array}{l}-0.012 \\
(-0.46)\end{array}$ & $\begin{array}{l}-0.012 \\
(-0.46)\end{array}$ & $\begin{array}{l}-0.011 \\
(-0.45)\end{array}$ & $\begin{array}{l}-0.011 \\
(-0.42)\end{array}$ \\
\hline Manual worker & & & $\begin{array}{r}\text { Reference } \\
\text { category }\end{array}$ & & \\
\hline Unemployed & $\begin{array}{l}-0.305^{* * *} \\
(-21.39)\end{array}$ & $\begin{array}{l}-0.305^{* * *} \\
(-21.38)\end{array}$ & $\begin{array}{l}-0.305^{* * *} \\
(-21.41)\end{array}$ & $\begin{array}{l}-0.305^{* * *} \\
(-21.43)\end{array}$ & $\begin{array}{l}-0.304^{* * *} \\
(-21.12)\end{array}$ \\
\hline Without occupation & $\begin{array}{l}0.027^{* *} \\
(2.28)\end{array}$ & $\begin{array}{l}0.027^{* *} \\
(2.28)\end{array}$ & $\begin{array}{l}0.027^{* *} \\
(2.28)\end{array}$ & $\begin{array}{l}0.027 * * \\
(2.29)\end{array}$ & $\begin{array}{l}0.027^{* *} \\
(2.28)\end{array}$ \\
\hline \multirow[t]{2}{*}{ Retired } & 0.007 & 0.007 & 0.007 & 0.007 & 0.008 \\
\hline & $(0.43)$ & $(0.44)$ & $(0.44)$ & $(0.44)$ & $(0.45)$ \\
\hline \multirow{2}{*}{ Farmer/fisherman } & 0.012 & 0.012 & 0.012 & 0.011 & 0.012 \\
\hline & $(0.49)$ & $(0.49)$ & $(0.49)$ & $(0.48)$ & $(0.49)$ \\
\hline \multirow{2}{*}{ Professional } & $0.178^{* * *}$ & $0.178^{* * *}$ & $0.178^{* * *}$ & $0.178^{* * *}$ & $0.177^{* * *}$ \\
\hline & $(10.26)$ & $(10.31)$ & $(10.30)$ & $(10.29)$ & $(10.31)$ \\
\hline Self-employed & $\begin{array}{l}0.068^{* * *} \\
(3.94)\end{array}$ & $\begin{array}{l}0.068^{* * *} \\
(3.95)\end{array}$ & $\begin{array}{l}0.068^{* * *} \\
(3.95)\end{array}$ & $\begin{array}{l}0.068^{* * *} \\
(3.95)\end{array}$ & $\begin{array}{l}0.068^{* * *} \\
(3.94)\end{array}$ \\
\hline Business propriator & $\begin{array}{l}0.152^{* * *} \\
(8.92)\end{array}$ & $\begin{array}{l}0.153^{* * *} \\
(8.91)\end{array}$ & $\begin{array}{l}0.153^{* * *} \\
(8.90)\end{array}$ & $\begin{array}{l}0.153^{* * *} \\
(8.87)\end{array}$ & $\begin{array}{l}0.153^{* * *} \\
(8.91)\end{array}$ \\
\hline \multirow[t]{2}{*}{ Employed professional } & $0.159^{* * *}$ & $0.159^{* * *}$ & $0.159^{* * *}$ & $0.159 * * *$ & $0.159^{* * *}$ \\
\hline & $(12.06)$ & $(12.02)$ & (12.03) & $(12.03)$ & $(12.02)$ \\
\hline General management & $\begin{array}{l}0.215^{* * *} \\
(12.61)\end{array}$ & $\begin{array}{l}0.215^{* * *} \\
(12.60)\end{array}$ & $\begin{array}{l}0.215^{* * *} \\
(12.59)\end{array}$ & $\begin{array}{l}0.215^{* * *} \\
(12.60)\end{array}$ & $\begin{array}{l}0.215^{* * *} \\
(12.61)\end{array}$ \\
\hline \multirow[t]{2}{*}{ Middle management } & $0.141^{* * *}$ & $0.141^{* * *}$ & $0.141 * * *$ & $0.141^{* * *}$ & $0.141^{* * *}$ \\
\hline & $(12.69)$ & $(12.65)$ & $(12.64)$ & $(12.59)$ & $(12.67)$ \\
\hline Employed position (desk) & $\begin{array}{l}0.088^{* * *} \\
(8.14)\end{array}$ & $\begin{array}{l}0.088^{* * *} \\
(8.14)\end{array}$ & $\begin{array}{l}0.088^{* * *} \\
(8.14)\end{array}$ & $\begin{array}{l}0.088^{* * *} \\
(8.14)\end{array}$ & $\begin{array}{l}0.088^{* * *} \\
(8.13)\end{array}$ \\
\hline Employed position (travel) & $\begin{array}{l}0.057^{* * *} \\
(6.41)\end{array}$ & $\begin{array}{l}0.057^{* * *} \\
(6.38)\end{array}$ & $\begin{array}{l}0.057^{* * *} \\
(6.38)\end{array}$ & $\begin{array}{l}0.056^{* * *} \\
(6.36)\end{array}$ & $\begin{array}{l}0.056^{* * *} \\
(6.32)\end{array}$ \\
\hline \multirow[t]{2}{*}{ Service sector } & $0.070^{* * *}$ & $0.070^{* * *}$ & $0.070^{* * *}$ & $0.070^{* * *}$ & $0.070^{* * *}$ \\
\hline & $(10.91)$ & (10.93) & $(10.92)$ & $(10.90)$ & $(10.89)$ \\
\hline Supervisor & $\begin{array}{l}0.069^{* * *} \\
(5.44)\end{array}$ & $\begin{array}{l}0.069^{* * *} \\
(5.44)\end{array}$ & $\begin{array}{l}0.069^{* * *} \\
(5.45)\end{array}$ & $\begin{array}{l}0.069 * * * \\
(5.46)\end{array}$ & $\begin{array}{l}0.069^{* * *} \\
(5.48)\end{array}$ \\
\hline Country/region FE & Yes & Yes & Yes & Yes & Yes \\
\hline Survey wave FE & Yes & Yes & Yes & Yes & Yes \\
\hline Linear country-spec. time trends & Yes & Yes & Yes & Yes & Yes \\
\hline Quadratic country-spec. time trends & Yes & Yes & Yes & Yes & Yes \\
\hline No. of observations & 629,930 & 629,930 & 629,930 & 629,930 & 629,930 \\
\hline No. of clusters & 40 & 40 & 40 & 40 & 40 \\
\hline $\mathrm{R}^{2}$ & 0.22 & 0.22 & 0.22 & 0.22 & 0.22 \\
\hline
\end{tabular}

Notes: OLS estimations. T-values in parentheses. Standard errors are clustered on the country/region level. Significance levels: ${ }^{*} .05<p<.1,{ }^{* *} .01<p<.05,{ }^{* * *}<.01$. 
Table A.5: Covariates of individual smoking behavior in 40 European countries and regions, 1990-2009

\begin{tabular}{|c|c|c|}
\hline & Male & Female \\
\hline Smoking ban & $\begin{array}{r}0.091 \\
(1.56)\end{array}$ & $\begin{array}{l}-0.067 \\
(-1.42)\end{array}$ \\
\hline $\ln ($ cigarette price $)$ & $\begin{array}{r}0.168 \\
(1.27)\end{array}$ & $\begin{array}{r}0.004 \\
(0.04)\end{array}$ \\
\hline $\ln ($ GDP per capita $)$ & $\begin{array}{l}0.500^{* *} \\
(2.25)\end{array}$ & $\begin{array}{l}0.720^{* * *} \\
(2.63)\end{array}$ \\
\hline Unemployment rate & $\begin{array}{r}0.010 \\
(1.33)\end{array}$ & $\begin{array}{l}0.028^{* * * *} \\
(2.85)\end{array}$ \\
\hline Inflation rate & $\begin{array}{l}0.005 \\
(0.49)\end{array}$ & $\begin{array}{l}-0.029^{* *} \\
(-2.48)\end{array}$ \\
\hline Other tobacco policies & $\begin{array}{r}0.008 \\
(0.74)\end{array}$ & $\begin{array}{l}-0.021 * * * \\
(-2.70)\end{array}$ \\
\hline $\ln ($ beer tax $)$ & $\begin{array}{l}-0.151^{* *} \\
(-2.46)\end{array}$ & $\begin{array}{l}-0.140^{* *} \\
(-2.12)\end{array}$ \\
\hline Age & $\begin{array}{l}0.117^{* * *} \\
(9.09)\end{array}$ & $\begin{array}{l}0.089^{* * *} \\
(4.51)\end{array}$ \\
\hline $\operatorname{Age}^{2} / 100$ & $\begin{array}{l}-0.222^{* * *} \\
(-8.14)\end{array}$ & $\begin{array}{l}-0.191^{* * *} \\
(-3.96)\end{array}$ \\
\hline $\operatorname{Age}^{3} / 1000$ & $\begin{array}{l}0.010^{* * *} \\
(5.45)\end{array}$ & $\begin{array}{l}0.007^{* *} \\
(2.13)\end{array}$ \\
\hline Education until less than age 15 & $\begin{array}{l}\text { Reference } \\
\text { category }\end{array}$ & \\
\hline Education up to age $16-19$ & $\begin{array}{l}-0.072 \\
(-1.25)\end{array}$ & $\begin{array}{r}0.102 \\
(1.00)\end{array}$ \\
\hline Education up to age 20 or more & $\begin{array}{l}-0.402^{* * *} \\
(-5.89)\end{array}$ & $\begin{array}{l}-0.304^{* *} \\
(-2.27)\end{array}$ \\
\hline Student & $\begin{array}{l}-0.745^{* * *} \\
(-4.48)\end{array}$ & $\begin{array}{l}-0.694^{* * *} \\
(-4.25)\end{array}$ \\
\hline Married & $\begin{array}{l}\text { Reference } \\
\text { category }\end{array}$ & \\
\hline Single with partner & $\begin{array}{l}0.253^{* * *} \\
(5.90)\end{array}$ & $\begin{array}{l}0.318^{* * *} \\
(6.58)\end{array}$ \\
\hline Single & $\begin{array}{l}0.187^{* * *} \\
(6.17)\end{array}$ & $\begin{array}{l}0.411^{* * *} \\
(10.73)\end{array}$ \\
\hline Divorced & $\begin{array}{l}0.742^{* * *} \\
(14.90)\end{array}$ & $\begin{array}{l}0.852^{* * * *} \\
(19.64)\end{array}$ \\
\hline Widowed & $\begin{array}{l}0.427^{* * *} \\
(7.52)\end{array}$ & $\begin{array}{l}0.378^{* * * *} \\
(8.41)\end{array}$ \\
\hline Other marital status & $\begin{array}{l}0.229^{* *} \\
(2.57)\end{array}$ & $\begin{array}{l}0.246^{* * *} \\
(3.23)\end{array}$ \\
\hline No children in $\mathrm{HH}$ under age 15 & $\begin{array}{l}\text { Reference } \\
\text { category }\end{array}$ & \\
\hline One child in $\mathrm{HH}$ under age 15 & $\begin{array}{l}-0.081^{* *} \\
(-2.22)\end{array}$ & $\begin{array}{l}-0.035 \\
(-1.15)\end{array}$ \\
\hline Two children child in $\mathrm{HH}$ under age 15 & $\begin{array}{l}-0.125^{* * *} \\
(-3.04)\end{array}$ & $\begin{array}{l}-0.177 * * * \\
(-4.36)\end{array}$ \\
\hline Three children in $\mathrm{HH}$ under age 15 & $\begin{array}{l}-0.173^{* *} \\
(-2.45)\end{array}$ & $\begin{array}{l}-0.153^{* * *} \\
(-2.83)\end{array}$ \\
\hline Four children in $\mathrm{HH}$ under age 15 & $\begin{array}{r}0.034 \\
(0.69)\end{array}$ & $\begin{array}{r}0.001 \\
(0.02)\end{array}$ \\
\hline No info about children in $\mathrm{HH}$ & $\begin{array}{l}0.190^{* * *} \\
(6.09)\end{array}$ & $\begin{array}{l}0.231^{* * * *} \\
(6.34)\end{array}$ \\
\hline Manual worker & $\begin{array}{l}\text { Reference } \\
\text { category }\end{array}$ & \\
\hline Unemployed & $\begin{array}{l}0.376^{* * *} \\
(7.19)\end{array}$ & $\begin{array}{l}0.137^{* * *} \\
(2.97)\end{array}$ \\
\hline Without occupation & $\begin{array}{l}-0.252^{*} \\
(-1.84)\end{array}$ & $\begin{array}{l}-0.165^{* * *} \\
(-3.43)\end{array}$ \\
\hline
\end{tabular}


Table A.5: (continued)

\begin{tabular}{lll} 
Retired & $-0.156^{* * *}$ & -0.021 \\
Farmer/fisherman & $(-2.80)$ & $(-0.22)$ \\
Professional & $(-7.31)$ & $-1.020^{* * * *}$ \\
& $-0.326^{* * *}$ & $(-5.55)$ \\
Self-employed & $(-4.31)$ & $(-1.17)$ \\
& $-0.176^{* * *}$ & -0.038 \\
Business propriator & $(-2.62)$ & $(-0.58)$ \\
Employed professional & $-0.327^{* * *}$ & -0.057 \\
& $(-5.24)$ & $(-0.53)$ \\
General management & $-0.536^{* * *}$ & $-0.499^{* * *}$ \\
& $(-5.84)$ & $(-5.92)$ \\
Middle management & $-0.500^{* * *}$ & $-0.273^{* * *}$ \\
& $(-6.26)$ & $(-2.84)$ \\
Employed position (desk) & $-0.521^{* * *}$ & $-0.445^{* * *}$ \\
& $(-9.28)$ & $(-7.35)$ \\
Employed position (travel) & $-0.533^{* * *}$ & $-0.336^{* * *}$ \\
& $(-8.24)$ & $(-5.34)$ \\
Service sector & $-0.156^{* * *}$ & 0.008 \\
& $(-2.73)$ & $(0.12)$ \\
Supervisor & $-0.241^{* * *}$ & $-0.158^{* * *}$ \\
& $(-4.65)$ & $(-2.82)$ \\
\hline \hline No. of obs. & $-0.252^{* * *}$ & $-0.287^{*}$ \\
Pseudo R & $(-2.80)$ & $(-1.80)$ \\
\hline
\end{tabular}

Notes: Logit estimations. Z-values in parentheses. Standard errors are clustered on the country/region level. Country fixed effects and country-specific time trends are included in the regression.

Significance levels: $* .05<p<.1,{ }^{* *} .01<p<.05,{ }^{* * *}<.01$. 
Figure A.2: Distribution of predicted propensities to smoke

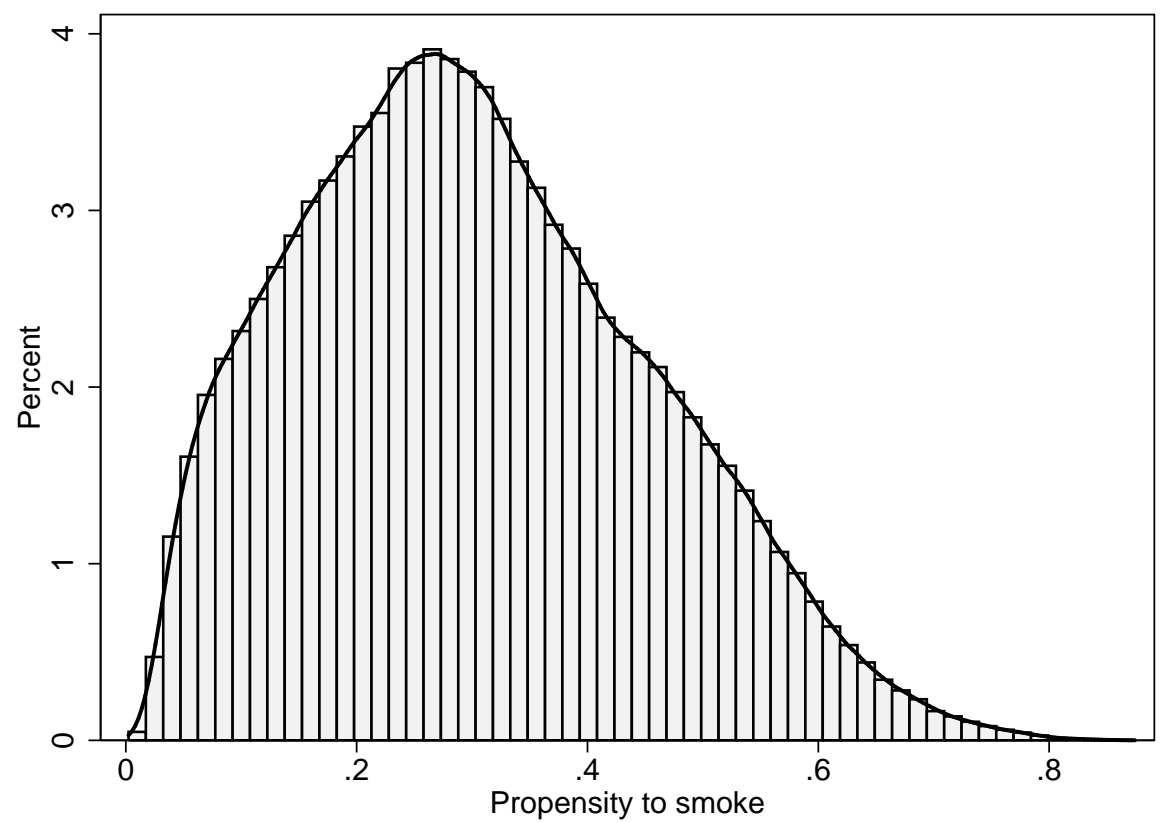

Notes: Distribution is for the sample of people studied in Table 2. 
Figure A.3: Actual smoking behavior for people with different smoking propensities

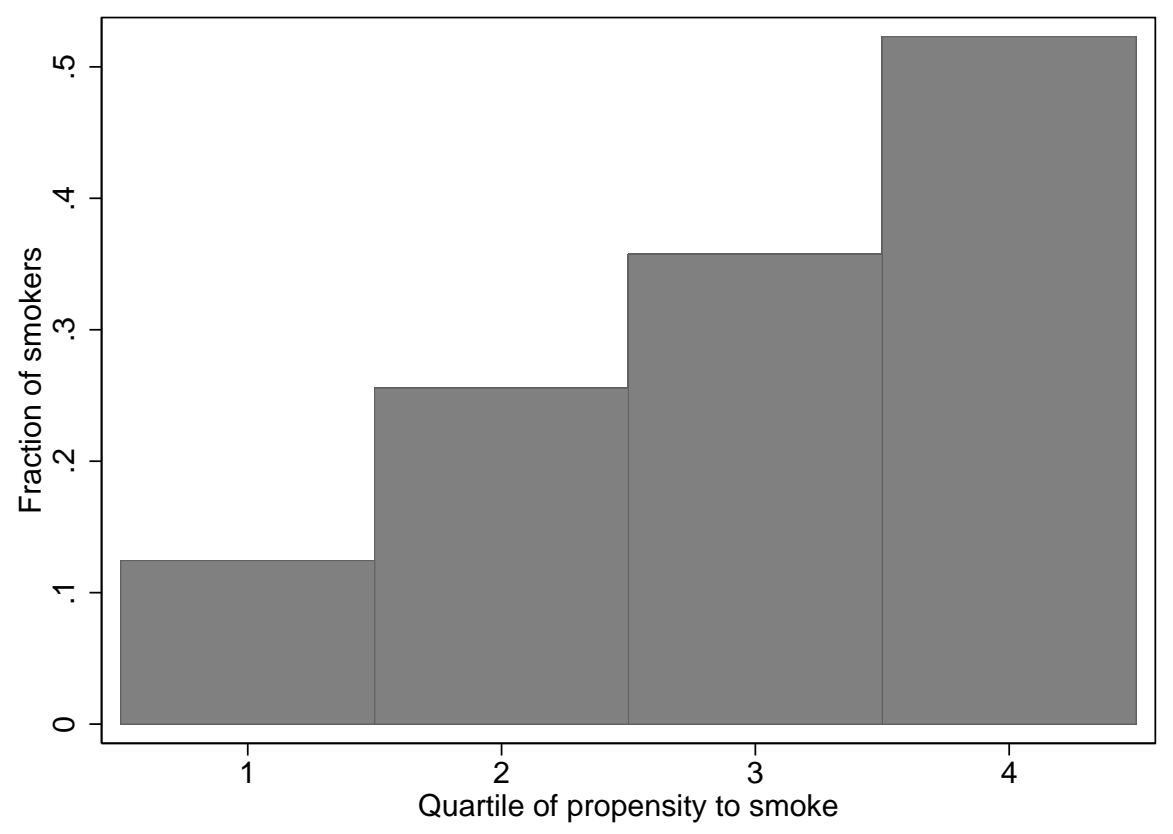

Notes: Mean values per quartile are based on within sample predictions of 126,264 observations. 
Table A.6: Covariates in the multinomial logit model for smokers, non-smokers and marginal smokers

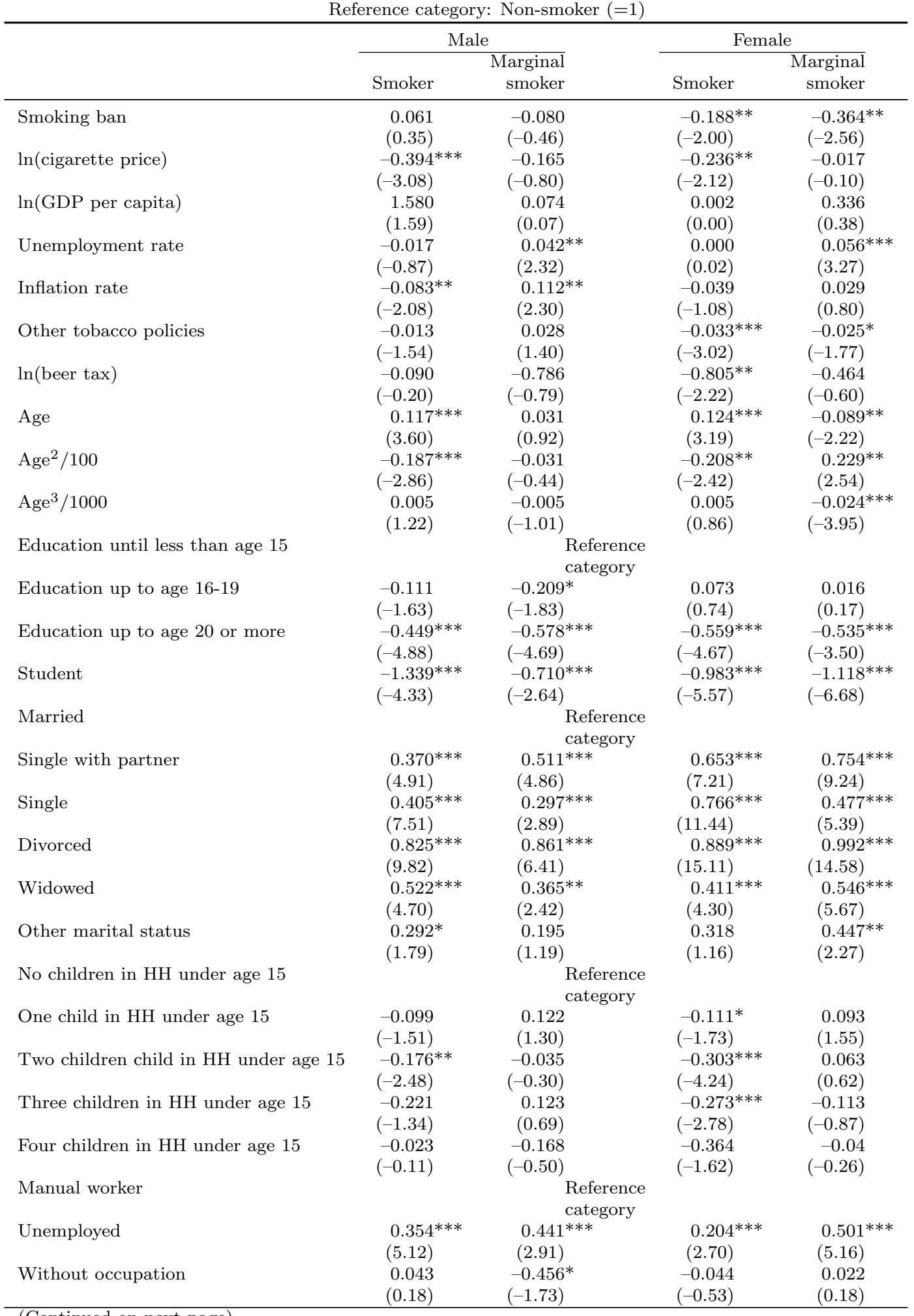


Table A.6: (continued)

\begin{tabular}{llllc} 
Retired & $-0.241^{* *}$ & 0.076 & -0.067 & $0.284^{*}$ \\
Farmer/fisherman & $(-2.30)$ & $(0.77)$ & $(-0.50)$ & $(1.79)$ \\
& $-0.722^{* * *}$ & $-0.694^{* * *}$ & $-1.529^{* * *}$ & 0.060 \\
Professional & $(-3.39)$ & $(-3.07)$ & $(-4.54)$ & $(0.18)$ \\
& $-0.510^{* * *}$ & 0.009 & -0.279 & 0.090 \\
Self-employed & $(-2.83)$ & $(0.04)$ & $(-1.26)$ & $(0.39)$ \\
Business propriator & -0.174 & -0.027 & -0.093 & -0.319 \\
& $(-1.34)$ & $(-0.18)$ & $(-0.65)$ & $(-1.31)$ \\
Emloyed professional & $-0.306^{* * *}$ & $-0.692^{* * *}$ & -0.018 & -0.180 \\
& $(-2.80)$ & $(-6.42)$ & $(-0.09)$ & $(-0.60)$ \\
General management & $-0.741^{* * *}$ & $-0.855^{* * *}$ & $-0.369^{*}$ & -0.362 \\
& $(-4.98)$ & $(-5.62)$ & $(-1.87)$ & $(-1.47)$ \\
Middle management & $-0.761^{* * *}$ & $-0.877^{* * *}$ & -0.083 & -0.586 \\
& $(-5.99)$ & $(-3.42)$ & $(-0.47)$ & $(-1.60)$ \\
Employed position (desk) & $-0.676^{* * *}$ & $-0.481^{* * *}$ & $-0.375^{* * *}$ & $-0.634^{* * *}$ \\
& $(-6.23)$ & $(-3.84)$ & $(-3.72)$ & $(-4.88)$ \\
Employed position (travel) & $-0.829^{* * *}$ & $-0.750^{* * *}$ & $-0.273^{* *}$ & $-0.373^{* *}$ \\
& $(-7.14)$ & $(-4.26)$ & $(-2.44)$ & $(-2.54)$ \\
Service sector & $-0.222^{* *}$ & $-0.324^{* *}$ & -0.025 & 0.285 \\
& $(-2.29)$ & $(-1.97)$ & $(-0.18)$ & $(1.52)$ \\
Supervisor & $-0.304^{* * *}$ & $-0.334^{* *}$ & $-0.223^{* *}$ & -0.082 \\
& $(-3.41)$ & $(-2.15)$ & $(-2.41)$ & $(-0.56)$ \\
& -0.136 & -0.048 & -0.076 & -0.202 \\
No. of obs. & $(-0.82)$ & $(-0.20)$ & $(-0.30)$ & $(-0.33)$ \\
No. of clusters & 18,687 & 18,687 & 23,868 & 23,868 \\
Pseudo R & 40 & 40 & 40 & 40 \\
\hline
\end{tabular}

Notes: Multinomial logit estimations separately for women and men. Z-values in parentheses. Standard errors are clustered on the country/region level. Country fixed effects are included in the regression.

Significance levels: ${ }^{*} .05<p<.1,{ }^{* *} .01<p<.05,{ }^{* * *}<.01$. 
Figure A.4: Distribution of predicted propensities to be non-smoker, smoker and marginal smoker
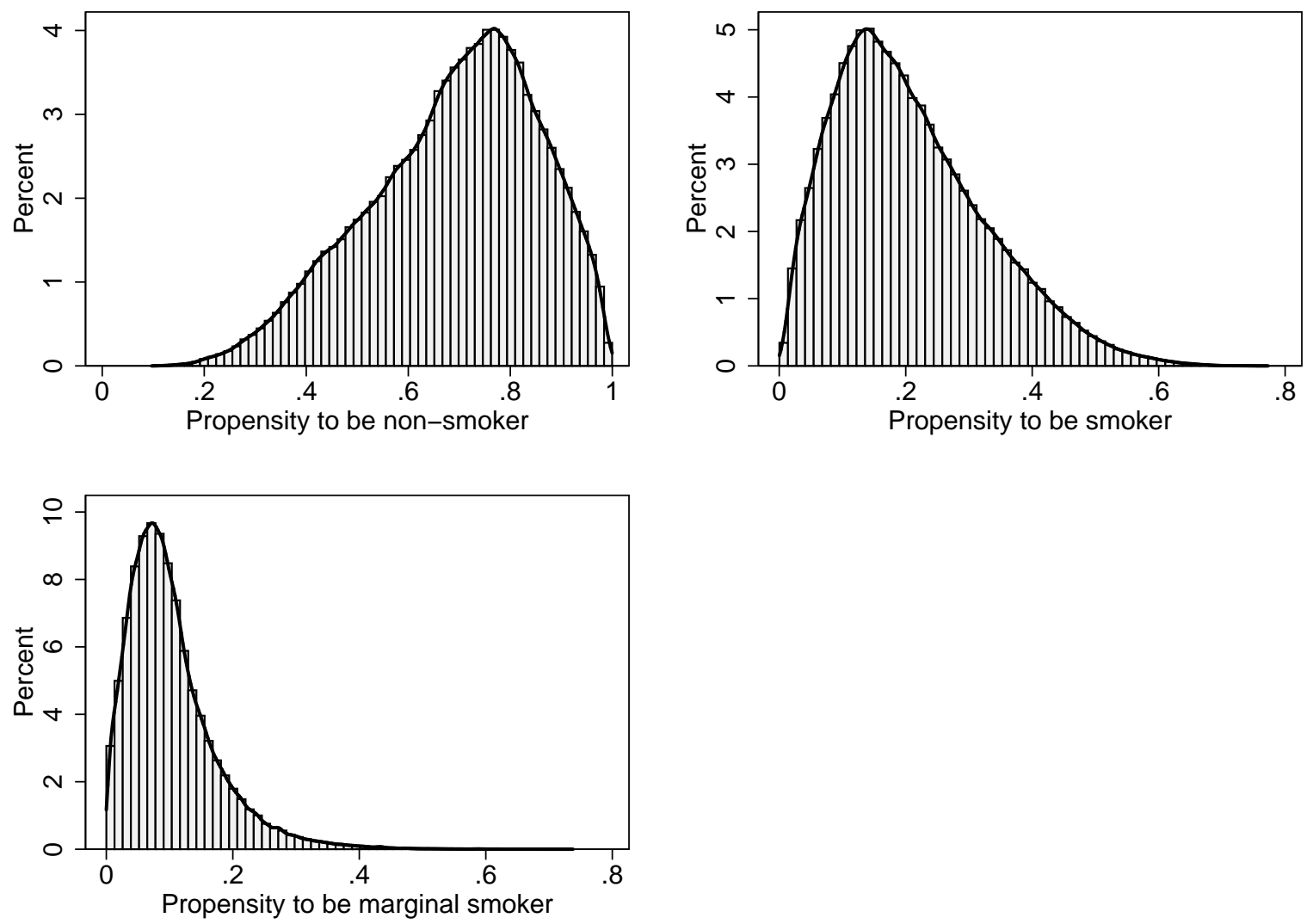

Notes: Distributions are for the sample of people studied in Table 4. 